\title{
Fixed-term Contracts and the Duration Distribution of Unemployment*
}

\author{
Maia Güell \\ Universitat Pompeu Fabra \\ CEP (LSE), CEPR and IZA
}

May 2003

\begin{abstract}
In the mid-1980s, many European countries introduced fixed-term contracts. This paper studies the possible implications of such reforms for the duration distribution of unemployment. I estimate a parametric duration model using cross-sectional data drawn from the Spanish Labor Force Survey from 1980 to 1994 to analyze the probability of leaving unemployment before and after the introduction of fixed-term contracts. I find that the difference in the probability of leaving unemployment between the short and long term unemployed increased after this reform. Semi-parametric estimation of the model also shows that for long spells, the probability of leaving unemployment decreased between the mid-1980s and the early 1990s.
\end{abstract}

Keywords: cross-sectional data, duration model, turnover.

JEL Classification codes: C41, J63, J64.

*I am very grateful to Melissa Clark, Erica Field, José Galdón, Nacho García, Maria Guadalupe, Bo Honoré, Luojia Hu, David Jaeger, Stepan Jurajda, Marco Manacorda, Alan Manning, Steve Nickell, Barbara Petrongolo, Elie Tamer, Merxe Tudela, Ernesto Villanueva and Jonathan Wadsworth for very useful discussions and suggestions, as well as, participants of the 2002 ESSLE, the Labor seminars at the CEP (LSE), Princeton and UPF; the Econometrics Reading Group at Princeton, the Econometrics seminar at the European University Institute and Hunter College and UAB seminar for their comments. I also thank the hospitality of the IR Section (Princeton University) where part of this work was completed. This research was supported by grant No. P98-1129-R from the Phare ACE Program. E-mail: maia.guell@upf.edu 


\section{Introduction}

In the mid-1980s, many European countries introduced fixed-term contracts in order to fight the high and persistent levels of unemployment that they had suffered since the mid-1970s. Prior to the mid-1980s, European labor markets had typically been characterized by a wide use of permanent contracts with high regulated firing costs. The idea behind this policy was to increase flexibility in the labor market by allowing employers the option of hiring workers under shorter contracts with negligible firing costs. ${ }^{1}$

Since their introduction, fixed-term contracts have been widely used, and an increasing number of new jobs are fixed-term (see OECD, 1993). European labor markets have become more dynamic in terms of worker turnover rates, but, contrary to expectation, the unemployment rate has remained largely unchanged (see table 1). The consequences of the introduction of fixed-term contracts have generated interest and concern among both academics and policy-makers (see Booth et al., 2002, and OECD, 2002). Much of the existing research on fixed-term contracts (or temporary contracts, TCs) ${ }^{2}$ has focused on their effectiveness in reducing unemployment. There is a wide consensus among economists that the introduction of such contracts does not necessarily increase employment despite the emergence of a dual labor market among employed workers. ${ }^{3}$ In this paper, I study the possible effect of TCs, through increased labor market flows, on the duration distribution of unemployment. In particular, I study the possibility that the pool of unemployed workers becomes segmented.

Along with the high rates of unemployment, another worrisome feature of European labor markets is the high proportion of unemployed workers who have been unemployed for a long

\footnotetext{
${ }^{1}$ See Grubb and Wells (1993) and OECD (1999) for a detailed description of fixed-term contract regulations in Europe.

${ }^{2}$ The terms fixed-term contract and temporary contract (TC) will be used interchangeably throughout this paper.

${ }^{3}$ See, among others, Aguirregabiria and Alonso-Borrego (1999), Alonso-Borrego et al. (1999), Bentolila and Dolado (1994), Güell (2000) and Saint-Paul (1996).
} 
period of time (see Machin and Manning, 1999). In Europe, on average, between 1983 and 1994, 48 percent of the unemployed had been in unemployment for more than 12 months (the long-term unemployed, LTU), while in the US this proportion was only 9 percent (see table 1). Therefore, it is important to investigate whether the introduction of TCs has improved the functioning of the labor market for the LTU.

In this paper, I provide some theoretical considerations of the effects of introducing TCs on the duration distribution of unemployment, and I then present an application to Spain, a particularly striking case. More precisely, I analyze the effects of TCs on the incidence of LTU, on the duration dependence of unemployment and on the outflow rate of the LTU workers.

In the mid-1980s, the Spanish unemployment rate was close to 20 percent, the highest of the OECD countries. In 1984, Spain introduced a temporary contract policy that was far more liberal than that of other European countries. In particular, while in some countries TCs were restricted to particular types of workers or sectors, there were no such restrictions in Spain. In fact, all workers in all occupations and sectors could be hired under a TC. Concerns that the extremely high levels of labor market regulation were responsible for Spain's high unemployment rate motivated this sweeping reform (see OECD, 1994). Figure 1 shows the evolution of the unemployment rate as well as the increase of the share of TCs from 1980 to 1996.

A decade after the introduction of fixed-term contracts, the unemployment rate in Spain had returned to pre-reform levels. Moreover, the share of fixed-term employees had become the highest in Europe, around 33 percent, while the European average was 11 percent (see table 1). As a consequence, in 1994, a second reform that restricted the use of TCs was implemented. Therefore, the Spanish experience between 1980 and 1994 appears to be particularly useful for studying the effects of these types of policies. ${ }^{4}$

\footnotetext{
${ }^{4}$ Clearly, it is also possible that during this period there were some underlying structural changes in the
} 
Although the effects of TCs on unemployment have been unsatisfactory, there have been other changes in other dimensions of the labor market that can reasonably be attributed to these flexibility measures. First, inflows and outflows from unemployment to employment have increased substantially over this period (see figures 2 and 3). TCs have played an important role in this increase in turnover during this period. After the 1984 reform, on average, as many as 94 percent of all newly registered contracts have been TCs (see figure 4) while previously it was around 20 percent. $^{5}$ Bover et al. (2002) and García-Pérez (1997) also find that TCs increase the employment chances of the unemployed in Spain. As for the inflows back to unemployment, on average, between 1987 and 1994, as many as 75 percent of these workers were separated from their jobs because their fixed-term contract came to an end. ${ }^{6}$ Another supporting fact is that, on average, the renewal rate of TCs into permanent ones has been very low, around 8 percent, which implies a large flow from non-renewed workers into unemployment. ${ }^{7}$ Finally, García-Serrano (1998) studies the role of TCs in worker turnover in Spain and concludes that these contracts account for the largest portion of the hiring and separations rates.

The increase in outflows from unemployment implied a second important change in the Spanish labor market relating to the long-term unemployment rates, which is also among the highest in Europe (see table 1). The incidence of LTU typically displays anti-clockwise loops over the business cycle (see Machin and Manning, 1999). As can be seen in figure 5, for a given unemployment rate, the incidence of LTU in Spain in the early 1990s is lower than in the mid-1980s. Comparing periods which are at the same point in the cycle, say from 1983 to 1985 and from 1992 to 1994, there has been a shift in the unemployment rate-LTU

Spanish economy, such as sectorial shocks. However, in terms of legal changes, the introduction of TCs was the main reform in the labor market during this period. In any case, as will be explained later, the important fact is that, in the labor market, these other possible changes materialized through temporary contracts.

${ }^{5}$ See Figure 1 in Bover et al. (2002).

${ }^{6}$ The inflow is measured by the unemployed who have duration less than 1 month.

${ }^{7}$ See Güell and Petrongolo (2000). 
relationship. In fact, this seems to be a common feature in several European countries (see table 1). As mentioned in Machin and Manning (1999), when the outflow rate increases at any duration of unemployment, the incidence of LTU tends to decline. Therefore, the lower incidence of LTU can also be attributed to the increased outflows that have occurred since the introduction of TCs.

Previous studies that estimate the probability of leaving unemployment in Spain find that there is a very strong duration dependence. ${ }^{8}$ In other words, ceteris paribus, unemployed workers with shorter unemployment spells have higher probabilities of leaving unemployment than those with longer spells. But an important question that remains is whether the introduction of TCs has changed the duration distribution of unemployment through changes in duration dependence. The aim of this paper is to analyze the changes in the probability of leaving unemployment for the short term unemployed relative to the LTU before and after the introduction of TCs in Spain.

As with many other countries, panel data are not always available. Panel data from the Spanish Labor Force Survey are only available after 1987. Therefore, to analyze the changes in duration dependence before and after the introduction of TCs, I use cross-sectional data drawn from the same survey for the years 1980 to 1994 . I exploit these data following the parametric duration model suggested by Nickell (1979a). ${ }^{9}$ In order to further study the changes in the probability of leaving unemployment among the LTU, I estimate a semiparametric version of Nickell's model and discuss the conditions under which such a model can be estimated.

The remainder of this paper is organized as follows. Section 2 provides some theoretical considerations of the introduction of TCs on the duration distribution of unemployment. Section 3 describes the data. Section 4 presents a duration model of the transition from

\footnotetext{
${ }^{8}$ See, for instance, Alba (1999), Bover et al. (2002), García-Pérez (1997), Jenkins and García-Serrano (2000) and Machin and Manning (1999).

${ }^{9}$ Andrés et al. (1989) also estimate this model using a 1985 data set from the Spanish Ministry of Finance.
} 
unemployment to employment. Section 5 presents the empirical results, and section 6 concludes.

\section{Theoretical Considerations}

In this section, I consider the different hiring rules used by firms and their implications for the duration distribution of unemployment. I assume that once TCs are introduced, unemployed workers are always hired under a TC. This is driven by firms' choices rather than workers' preferences for temporary jobs. ${ }^{10}$ When hiring, firms can either choose randomly among the pool of unemployed workers or, alternatively, they can rank applicants by their spells of unemployment, hiring first those workers with the shortest duration of unemployment (see Blanchard and Diamond, 1994).

The introduction of TCs increases outflows from unemployment to employment since they are less costly than permanent contracts. As Machin and Manning (1999) show, when the outflow rate increases at any duration of unemployment, the incidence of LTU tends to decline. This implies that, independently of the hiring rule adopted by firms, the share of LTU will be reduced after the introduction of TCs (as figure 5 shows). The intuition behind this result is that, even if TCs do not increase (directly) the outflow rate of the LTU, as long as other unemployed workers with shorter spells become employed, then there is less build-up into longer spells.

However, the different hiring rules adopted by firms can have different effects on the duration dependence of unemployment. It is important to note that, to the extent that firms do not hire randomly, it is quite possible that duration dependence might have increased after the introduction of TCs (despite the lower incidence of LTU). As Blanchard and Diamond (1994) show, if firms rank unemployed workers and hire those with the shortest spells of

\footnotetext{
${ }^{10}$ As mentioned, since the introduction of TCs, almost all new contracts are of this type. Moreover, on average, from 1987 to 1994, as many as 89 percent of temporary workers reported that they were holding a TC because they could not find a permanent one.
} 
unemployment, then the exit rate from unemployment is a decreasing function of duration.

Consider two extreme situations. First, assume that all unemployed workers are homogeneous and that only duration of unemployment affects workers' probability of leaving unemployment. In this case, the short-term unemployed exit first after the introduction of TCs. Contrary to the situation prior to the introduction of TCs, their employment spell under TCs is shorter and, at the end of their TC, they go back to unemployment. Once in unemployment, they are again the unemployed with the shortest spell and thus with the highest re-employment probability. Therefore, the introduction of TCs could cause that the LTU, even if fewer in number, to experience higher persistence in unemployment.

Second, consider the other extreme model in which only certain key characteristics make unemployed workers more likely to be re-employed with a TC (for instance, gender, age or education). Similar dynamics to the ones explained above arise. After the introduction of TCs, workers with such characteristics enjoy higher exit rates than workers without such characteristics. And, as long as they maintain these characteristics, they continue to have a higher re-employment probability when they return to unemployment after their TC finishes. Therefore, the introduction of TCs can imply that workers without such characteristics tend to experience longer spells of unemployment than the others.

Therefore, to the extent that firms do not hire randomly, TCs will tend to always be enjoyed by the same group of unemployed workers. This implies that the duration dependence of unemployment will increase. However, this type of policy could still be Pareto efficient if the probability of exiting unemployment for those workers who do not get a TC remains unaffected.

This may not be the case for the following reason, however. Before the introduction of TCs, the short term unemployed were also be the first to leave unemployment whenever there was a job offer. However, the fact that they were less likely to go back to unemploy- 
ment because they were hired under a permanent contract implied that the all the other unemployed would move up in their ranking position, increasing their relative probability of leaving unemployment when a new offer arrived. Similarly, when considering some key employability characteristics of workers, the fact that workers who get TCs return to unemployment implies that these characteristics would be even more concentrated among unemployment spells, implying again a lower probability for the other unemployed workers to exit.

Therefore, the introduction of TCs can generate a segmented unemployment pool. That is, some unemployed workers will be constantly churning from unemployment to employment under TCs, while the other unemployed workers will not exit unemployment, experiencing longer durations of unemployment.

\section{The Data}

I use the Spanish Labor Force Survey (Encuesta de la Población Activa, EPA), which is carried out quarterly on a sample of some 60,000 households. ${ }^{11}$ It is designed to be representative of the total Spanish population and contains very detailed information about the labor force status of individuals.

My sample contains data from the second quarters of each year from 1980 to 1994 . The time span of the sample is an important feature of the data because it will allow me to analyze the characteristics of the unemployed before and after the introduction of TCs. Unfortunately, a natural experiment approach cannot be used to assess the effect of the introduction of TCs on the duration distribution of unemployment, since all the workers were eligible for these new contracts and thus there is no control group. However, as explained above, TCs played an important role in changing the labor market flows, and therefore it is reasonable to expect that most of the changes in the duration distribution of unemployment

\footnotetext{
${ }^{11}$ For a more detailed description, see http://www.ine.es/dacoin/dacoinme/inotepa.htm.
} 
over this period are related to the introduction of TCs. All the unemployed people in the sample are asked how long they have been looking for a job. This search time will be used as the individual's uncompleted duration of unemployment. ${ }^{12}$

As will be discussed, one main assumption of the econometric model is that the composition of the flow into unemployment is fixed over some period of time prior to any particular year analyzed. For this reason, I have excluded women from my sample since this assumption may be too strong for them. ${ }^{13}$ Thus, my sample includes all men who are unemployed and who report how long they have been searching for a job. ${ }^{14}$ I exclude men aged 65 or older because transitions to non-employment are more likely for this group. Since I want to focus on the effects of TCs on the existing distribution of unemployment, I will also exclude first-job seekers. This leaves me with a sample of 80,790 unemployed male workers.

One advantage of the cross-sectional EPA (relative to the currently available panel EPA ${ }^{15}$ ) is that it contains information on the region of residence as well as some household characteristics. However, until 1987 there was no information on unemployment benefits or on the reason for previous job loss. In order to fully exploit all the relevant information contained in the data, my analysis will be carried out in two parts. First, I use all the years of the sample, from 1980 to 1994 . The analysis is undertaken with those variables common to all sample years. This first part of the analysis thus exploits information for a very long time period at the expense of some relevant variables only available in the most recent years. These additional variables will be exploited in the second part of the analysis for those years for which they are available, from 1987 to 1994.

Explanatory variables available for the whole sample period include personal character-

\footnotetext{
${ }^{12}$ In steady state, the average uncompleted duration of unemployment is proportional to the average completed duration of unemployment (see Layard et al., 1991).

${ }^{13}$ This is not restrictive since females have a higher incidence of fixed-term contracts.

${ }^{14} \mathrm{~A}$ formal test of this stationarity assumption for this sample is undertaken in section 4 .

${ }^{15}$ See Bover et al. (2002).
} 
istics of the individual such as age, education and marital status, as well as some household characteristics such as the number of children and the number of working adults in the household. Finally, the local unemployment rate is also included to capture business cycle effects. ${ }^{16}$ This quarterly regional unemployment rate will be the only time-varying regressor. ${ }^{17}$ For the second part of the analysis, two more variables are available: a dummy variable that indicates if the worker receives unemployment benefits (UI) ${ }^{18}$; and a dummy variable indicating whether the reason for separation from the previous job was the ending of a TC (endTC).

Before the 1984 reform, TCs were only allowed for seasonal jobs. One key feature of the reform was that it allowed the use of TCs for jobs that are not necessarily seasonal. The higher share of TCs in total employment after the reform can be mainly attributed to their widespread use in non-seasonal jobs (see Güell and Petrongolo, 2000). Although the variable that indicates the reason for job loss was not available before 1987, the workers who were unemployed because their TC ended could only be those who had held a seasonal TC. Therefore, it is likely that the reform generated an exogenous increase in the number of workers who lost their job due to the expiration of a (non-seasonal) TC. ${ }^{19}$ The reason-forjob-loss is therefore a potential source of identification of the change in duration dependence after the introduction of TCs. This variable is very important for my purpose since it can

\footnotetext{
${ }^{16}$ See Bover et al. (2002) for a more detailed study of business cycle effects on unemployment duration.

${ }^{17}$ Unemployment rate at the regional level includes 50 provinces within Spain.

${ }^{18}$ During the period of study there were two minor reforms that increased the generosity of unemployment insurance in 1984 and of the unemployment assistance system in 1989. These reforms could have reduced the probability of job acceptance. However, as figure 3 shows, the outflow rate increased for the whole period, which indicates that the effect of TCs was much more important. Finally, in 1992 there was a more important reform that reduced the generosity of the unemployment insurance. The motivation for this reform was the increased inflows and outflows from unemployment through TCs, which generated an important deficit in the Spanish unemployment benefit system. This reform could have also contributed to increase the probability of leaving unemployment. However, its effect would be present at most in the last 2 years my sample.

${ }^{19}$ This variable distinguishes between the end of a seasonal TC and a "general" TC (the TCs introduced in 1984). Between 1987 and 1994, the number of people who have finished a seasonal TC have remained constant; while the number of people who have finished a "general" TC has increased substantially: from 13 percent of the unemployed in 1987 to 26 percent in 1994.
} 
potentially capture all the unemployed workers that enjoy the greater employment chances provided by this type of contract. Separate estimation of the model will be done for these workers.

Table 2 reports average sample values for the whole sample (column 1) as well as for each subsample for which a different model will be allowed (columns 2 to 7 ). Column 2 corresponds to the sample for the years before the reform. Columns 3 to 7 correspond to different samples for the years after the reform. ${ }^{20}$ First, the whole period after the reform (column 3); column 4 only considers the years 1992 to 1994, which correspond to the years which are at comparable points of the business cycle as the years before the reform (see figure 5). Column 5 reports the values for the years from 1987 to 1994, for which more variables are available, and finally, columns 6 and 7 correspond to the unemployed who ended a TC and the ones who were separated for other reasons for the years 1987 to 1994. The (uncompleted) duration of unemployment for the different sub-samples is also reported. As mentioned, this should be compared carefully for sample years corresponding to different points of the cycle. For the last two columns, however, it can be seen that people who are unemployed because of the ending of a TC have about half the (uncompleted) duration of the workers who lost their job for other reasons.

As will be discussed in the next section, in order to estimate the method proposed by Nickell (1979a), it is necessary to complement these cross-sectional data with historical time series of the inflows into unemployment. Unfortunately, the EPA does not offer a long time series on inflows into unemployment. ${ }^{21}$ I use the monthly registered data on unemployed and

\footnotetext{
${ }^{20}$ Separating the period after the reform into two periods according to the importance of TCs in the economy implies similar qualitative results to the ones found here (see Güell, 1999).

${ }^{21}$ The inflow rate could be obtained from those unemployed that report spells of less than 1 month, although the "heaping" problem particularly affects this category (people approximate to 1 month). Moreover, the EPA questionnaires have changed three times regarding the unemployment search time (see the Appendix A, for details). This implies that after 1987, this duration category is even more underepresented (since the answer "less than 1 month" is not allowed explicitly). Therefore there is a rupture in the series after 1987 due to the change in the questionnaire.
} 
new contracts that are available since $1978 .^{22}$ These data, from the Spanish Employment Office (INEM), allow me to construct monthly (male) inflows into unemployment. Since only those unemployed who have worked before can claim unemployment insurance, first-job seekers generally do not register at the Employment Office. This reinforces the decision to exclude this group from my analysis.

\section{Econometric Specification}

My sample has only cross-sectional data on uncompleted spells of unemployment. I will estimate the hazard rate of leaving unemployment following the method proposed by Nickell (1979a). The main requirement for implementing this method is historical data on the inflows into unemployment. The intuition behind this duration model is that the crosssectional data represent the unemployed who have "survived" with different durations at time $t$, while the inflow data represent the population "at risk" at different points in time. Generally, these data are easily available at the aggregate level. As Nickell shows, assuming that the composition of the flow into unemployment is fixed over time, the model can be estimated. As it will be discussed later, the frequency of these inflow data is an important issue to be considered in order to estimate such model, especially semi-parametrically.

Suppose that the probability of leaving unemployment from time $t$ to time $t+1$ for an unemployed individual $i$, conditional on having entered unemployment at time $t-s$ and on being unemployed at $t$ is given by

$$
h_{i}(t, s)=h\left(x_{i}\left(t_{i}, s\right), t, s\right)
$$

where $t_{i}$ is the date in which the interview took place (in my case, the second quarter of every different year considered) and $x_{i}$ are the relevant characteristics of the individual $i$, which include the individual's regional unemployment rate during all the spell of unemployment.

\footnotetext{
${ }^{22}$ Another advantage of these data is their monthly frequency. This feature is very important for the semi-parametric estimation of the model.
} 
I have specified $h$ to depend on $t$. More precisely, I allow the hazard function to be different for different time periods. For example, the hazard for the years before the reform can be different from the hazard for the years after the reform. However, within a sub-period, $h$ does not depend on $t$. That is, for example, the same function is assumed for the different years prior to the reform (as in Nickell, 1979a).

To write the likelihood, it is necessary to derive the probability for an individual of being unemployed at time $t$. First, let $S_{i}(t, v)$ be the probability individual $i$ of being (remained) unemployed at time $t$ conditional on having entered unemployed at time $t-v$. Therefore

$$
S_{i}(t, v)=\prod_{\tau=1}^{v}\left(1-h\left(x_{i}(t, \tau), t, \tau\right)\right), \text { for } v \geq 1
$$

Suppose that the probability of an individual $i$ of having entered unemployment at time $\tau$ is given by $u_{i}(\tau)$. Then the probability of being unemployed at time $t, U_{i}(t)$, is given by

$$
U_{i}(t)=\sum_{\tau=0}^{\infty} u_{i}(t-\tau) S_{i}(t, \tau)
$$

It is then possible to write the likelihood for an unemployed individual in my sample, that is the probability of having entered unemployment at time $t-v$ conditional on being unemployed at time $t$, as

$$
L_{i}=\frac{u_{i}\left(t_{i}-v\right) S_{i}\left(t_{i}, v\right)}{\sum_{v=0}^{\infty} u_{i}\left(t_{i}-v\right) S_{i}\left(t_{i}, v\right)}
$$

For early years of the sample, the duration of unemployment is presented in the form of bands (see Appendix A, first column). That is, given the date of the interview, $t_{i}$, the individual could have entered unemployment at any time between $t_{i}-a_{i}$ and $t_{i}-b_{i}$. Therefore given my data, the likelihood becomes ${ }^{23}$

$$
L_{i}=\frac{\sum_{v=a_{i}}^{b_{i}} u_{i}\left(t_{i}-v\right) S_{i}\left(t_{i}, v\right)}{\sum_{v=0}^{\infty} u_{i}\left(t_{i}-v\right) S_{i}\left(t_{i}, v\right)}
$$

\footnotetext{
${ }^{23}$ Aggregating the data after 1987 into the same duration groups as the earlier period gives the same qualitative results as those obtained here (see Güell, 1999).
} 
Obtaining prior estimates of $u_{i}$, say $\widehat{u}_{i}$, I can then write down the likelihood for my unemployed sample of individuals, $i=1, \ldots, I$ as

$$
L=\prod_{i=1}^{I}\left(\frac{\sum_{v=a_{i}}^{b_{i}} \widehat{u}_{i}\left(t_{i}-v\right) S_{i}\left(t_{i}, v\right)}{\sum_{v=0}^{\infty} \widehat{u}_{i}\left(t_{i}-v\right) S_{i}\left(t_{i}, v\right)}\right)
$$

There is one last thing to be specified in order to compute this likelihood function. This has to do with the infinite sum in the denominator. I will assume that for long enough durations, the conditional probability specified in (4.1) does not depend on duration and that the estimated probability of having entered unemployment is a constant. In particular, I make these assumptions for durations greater than 36 months. ${ }^{24}$ The corresponding $\widehat{u}$ is the average over the calendar year corresponding to 36 months of duration of unemployment for every individual $\left(u_{i, 36}\right)$. Finally, the likelihood to be maximized is as follows

$$
L=\prod_{i=1}^{I}\left(\frac{\sum_{v=a_{i}}^{b_{i}} \widehat{u}_{i}\left(t_{i}-v\right) S_{i}\left(t_{i}, v\right)}{\sum_{v=0}^{36} \widehat{u}_{i}\left(t_{i}-v\right) S_{i}\left(t_{i}, v\right)+\frac{u_{i, 36}}{h_{i}(36)} S_{i}\left(t_{i}, 36\right)}\right)
$$

The probability of individual $i$, with current characteristics $x_{c i}$, having entered unemployment at time $\tau$ is defined by

$$
u_{i}(\tau)=k\left(x\left(x_{c i}, \tau\right), \tau\right) \frac{\text { aggregate flow into unemployment in month } \tau}{\text { aggregate employment in month }(\tau-1)}
$$

where $k(x(),. \tau)$ is the proportion of the inflow into unemployment at time $\tau$ with characteristics $x$. Assuming that $k$ is independent of time, this probability can be estimated by

$$
\widehat{u}_{i}(\tau)=\text { constant } \times\left(\frac{\text { aggregate flow into unemployment in month } \tau}{\text { aggregate employment in month }(\tau-1)}\right)
$$

where the constant (which can depend on $x_{c i}$ ) cancels out in the likelihood function.

Estimation of (4.7) using cross-sectional data from time $t$ requires this stationarity assumption for the period $t$ to $t-36$, that is, during the 3 years prior to a given cross-section.

\footnotetext{
${ }^{24}$ Between 1987 and 1994, on average, only 7 percent of the unemployed had a duration greater than 3 years.
} 
There are two ways by which $k(x(., \tau), \tau)$ is affected over time. First, to assume that $k(x(., \tau),$.$) is constant is to assume that any changes in relevant characteristics over time are$ small. This corresponds to the standard assumption of time unvarying regressors. Second, assuming that $k(x(),. \tau)$ is constant also means that there are small changes in the proportions of individuals with particular characteristics in the inflow into unemployment. This point is more difficult to test, mainly because the inflow data from the Spanish Employment Office are not available for the different relevant characteristics. The only disaggregation is by gender. ${ }^{25}$ The solution adopted regarding this issue has been to choose a sample of individuals for whom this assumption is more plausible. I concentrate my analysis on men who have worked before and have the highest attachment in the labor market. A feature of this sample is that it excludes inflows from inactivity to unemployment which are more affected by the business cycle. ${ }^{26}$

However, it is possible to test this stationarity assumption after 1987 using the EPA crosssectional data. After this year, the survey contains information on job tenure of employed workers. This allows me to construct individual inflow rates. I construct a variable that takes a value of one for unemployed workers with duration less than a month and zero for the employed workers in the same cross-section with tenure of at least a month. I separately regress this inflow variable on all the observable individual characteristics interacted with year dummies for three year periods. ${ }^{27}$ Table 12 in Appendix $\mathrm{C}$ reports the value of the $\chi^{2}$ test and the associated p-value in brackets for the hypothesis that the composition of inflows within the three year window by each observable characteristic is constant. Column (7) in this table reports the results corresponding to the stationarity assumption for the whole period 1987-1994. Overall the results in this table indicate that the stationarity assumption

${ }^{25}$ Nickell (1979a and 1979b) points out the same problem for the UK.

${ }^{26}$ See van den Berg and van der Klaauw (2001) for a model in which micro and macro data are combined and the business cycle is allowed to affect the composition of inflow into unemployment.

${ }^{27}$ The variables UI and endTC cannot be calculated in an exact way for employed workers. 
is plausible for the sample of individuals chosen for the period 1987-1994.

I will first specify $h(t, s)$ following a proportional hazard model where the underlying baseline is a Weibull distribution, which is the simplest specification in which it is possible to capture the impact of the average exit rate and duration dependence (see Machin and Manning, 1999). ${ }^{28}$ That is,

$$
h_{i}(t, s)=1-\exp \left(\int_{s}^{s+1} \lambda(u) d u\right), \text { where } \lambda(s)=-\exp \left(x_{i}^{\prime} \beta\right) \lambda_{0}(s)
$$

and

$$
\lambda_{0}(s)=\alpha s^{\alpha-1}
$$

In order to further investigate the changes in the relative probability of leaving unemployment of the LTU, I re-estimate the model allowing a more flexible baseline hazard. The parametric estimation only allows me to analyze this question partially since the baseline hazard (see (4.11)) monotonically decreases with duration, so changes in the duration dependence parameter $(\alpha)$ will imply shifts of the whole base-line function.

Given the grouping of the duration data, a piecewise constant baseline hazard will be estimated. $^{29}$ Since I want to focus on changes in the probability of leaving unemployment for the LTU, I estimate three different steps which capture the very short-term unemployed (less than 6 months), a middle group (6 to 11 months) and the LTU (12 months or more).

It is important to note how the frequency of the inflow data plays a role in the estimation. In order to estimate the model, it is crucial that each duration group (the population that has survived and that we observe at time $t$ in the cross-section with duration $s$ ) can be matched unequivocally with its population at risk, namely the inflow at time $t-s$. If this condition did not hold (for instance, if the inflow at $t-s$ could be attached to more than one survival

\footnotetext{
${ }^{28}$ The results obtained there are qualitatively the same as those obtained with a logit distribution specification (see Güell, 1999).

${ }^{29}$ For comparison reasons, the same steps will be estimated for the years after 1987.
} 
group) an identification problem would arise, since a given inflow point could correspond to more than one duration group. In this case, it would not be possible to estimate a separated step for such a group. Let $s_{i}$ be the frequency of the inflow data. That is, we observe the inflow data at period $t, t-s_{i}, t-2 s_{i}$, etc. In the cross-section each duration group has duration $s$ (which depends on how the durations are aggregated). It is then crucial that $s_{i} \leq s$, so that a different step can be estimated for each duration group.

When the inflow is less frequent than the duration groups, then the step-wise assumptions (or even the parametric) will not suffice to estimate such a model. Further assumptions could be made to recover, for instance, monthly inflows from quarterly inflows. However, this would seem to be less appropriate in the semi-parametric case. As mentioned earlier, the inflow data is monthly. The duration groups of the cross-sectional data vary over time. Before 1987, the grouping of the data is quarterly (except for the first group), then 6 months and then yearly. After 1987, the grouping is monthly (if duration is less than 2 years) and then yearly. Therefore, there is no identification problem.

Finally, the estimates presented do not attempt to control for possible unobserved heterogeneity. ${ }^{30}$ Therefore the term duration dependence can be interpreted in a loose sense, that is, as a reduced form duration dependence after integrating out unobserved heterogeneity. However, given that Bover et al. (2002) as well as Canziani and Petrongolo (2001), using the panel version of the same data set, find that results do not change qualitatively after controlling for unobserved heterogeneity, I am more confident about the "duration dependence" found in my estimates. Clearly, the usual limitations in duration analysis apply: it could be the case that unobserved heterogeneity has changed before and after the introduction of fixed-term contracts and that this drives the results. However, there is no obvious reason to be concerned that this is particularly important in this context.

\footnotetext{
${ }^{30}$ In other words, I assume that unobserved heterogeneity has not changed before and after the introduction of fixed-term contracts.
} 


\section{Empirical Results}

I now estimate the hazard of leaving unemployment as modeled in the previous section. First, I estimate the Weibull base-line hazard specified in (4.11). Table 3 reports the estimates for the whole sample, 1980 - 1994. Every variable is interacted with a post-reform dummy (d8594, which takes value 1 for years from 1985 to 1994). The duration dependence parameter is statistically different before and after the reform. Figure 6 plots the hazard of leaving unemployment for the reference category estimated by this regression for the years before and after the reform. As can be seen, in the years after the reform the duration dependence of unemployment is much higher than before. For durations of less than 5 months, the probability of leaving unemployment is much higher than before. But the reverse is true for durations of 6 months or more.

The effects of the individual characteristics on the probability of exiting unemployment are fairly standard and consistent with previous studies (see Alba, 1999, and Bover et al., 2002). The re-employment probability decreases with age. Being married substantially increases the probability of finding a job. This has to do with lower reservation wages of these individuals given their household responsibilities, and for the same reason their attachment to the labor market is strong. Similarly, the effect of the number of children is positive, but small. Also, the effect of the number of working adults in the household is negative, but again, not very large. The estimated coefficients on education (secondary education or more) are negative for the pre-reform years, but positive afterwards. The former may be partially

explained by the fact that few people with a university degree stayed unemployed before the reform. The latter accords with existing results, such as Bover et al. (2002) who find that secondary education has no significant effect while a university degree has a positive effect on the re-employment probabilities for the period 1987-94.

While the period before the reform (from 1980 to 1994) is a recession, in the period after 
the reform there are some years of expansion (from 1985 to 1991) and some years of recession (from 1992 to 1994). As mentioned before, LTU typically displays anti-clockwise loops over the cycle implying that the incidence of LTU is generally higher in an expansion than in a recession (see Machin and Manning, 1999). This can imply that duration dependence is higher in expansion years. Indeed, when estimating the probability of leaving unemployment for the post reform period with each variable interacted with a recession dummy ( $d 9294$, which takes value 1 for the recession years), I find that this is the case (see table 4). However, comparing the estimated parameter of the duration dependence for the recession years, it is still lower than in the pre-reform period (see table 8, column 4$).{ }^{31}$

A further check of the increase of duration dependence after the introduction of TCs, despite the fact there are some expansion years in the post reform period, is to compare the years 1983 and 1992, which are the most comparable in terms of unemployment rates. Table 5 reports these estimates, where $d 92$ takes value 1 for the year 1992 . As can be seen, the main result still holds.

The number of variables available in the Spanish Labor Force Survey has increased over time. Therefore, I estimate a second set of regressions in which more variables are included for the period 1987-1994. The inclusion of more variables can affect the estimated duration dependence parameter. Therefore, it is important to check whether the above result is affected by the exclusion of these variables. Table 6 displays the results of the estimations without the UI dummy and the end-of-temporary-contract dummy; the estimations including only one of the two variables; and the estimation including both variables. As expected, the parameter of duration dependence increases with the different specifications. However, it is always lower than in the pre-reform period. ${ }^{32}$

\footnotetext{
${ }^{31}$ Testing that the duration dependence parameter in these recession years is the same as in the pre-reform period (that is, $\alpha=0.849$ ) gives the test statistic $z=13.51$. Therefore, the null hypothesis is rejected at standard levels of significance.

${ }^{32}$ Although these regressions are not strictly comparable, since the inclusion of additional variables modifies the estimated $\alpha$ upwards, this comparison is more restrictive than it should be.
} 
The effects of the variables also included in the previous regressions remain very similar. As can be seen, the effect of UI is positive. At first glance, this result may be surprising if one has in mind the standard disincentive effect from job search theory (see Mortensen, 1970 and 1977). ${ }^{33}$ There are several possible reasons for this result. First, the UI variable is only an indicator of whether the unemployed person is receiving benefits when being interviewed. There is wide consensus that the effects of unemployment benefit levels are far from robust, being in general not very significant and of small size, and that other dimensions of unemployment compensation may be more important, such as duration of benefits (see Atkinson and Micklewright (1991) for a review). ${ }^{34}$

Secondly, Alba (1999) and Bover et al. (2002) find that the effect of receiving unemployment is significant and quite sizeable, but that this effect is reduced over the spell of unemployment. This can be seen by simply calculating the correlation between UI receipt and duration of unemployment for different durations (see the Appendix B). Indeed, this correlation is higher at shorter durations, suggesting that the disincentive effect is present for short durations. But, for long durations not only it is not negligible, but it is negative. Wadsworth (1990) and Schmitt and Wadsworth (1993) exploit the idea that UI facilitate search by providing income with which to finance job search efforts (the job offers effect). These studies compare the search behavior of benefit claimants and non-claimants. They find that non-claimants search harder during the initial stages of unemployment when benefits may provide a temporary leisure subsidy to benefit claimants. As unemployment duration lengthens, search activities fall for both groups, but benefit recipients are able to maintain a higher level of search effort and therefore have a relatively higher probability of receiving

\footnotetext{
${ }^{33}$ However, Toharia (1997) reviews different studies on the disincentive effects of UI in Spain and concludes that, on the whole, the studies available are not conclusive.

${ }^{34}$ Moreover, in cross-sectional data, the fraction of UI recipients can be underestimated for two reasons. First, some unemployed can be interviewed once their UI has already expired and they can report they are not recipients of UI. Second, in Spain, it is often the case that the unemployed start receiving benefits with some delay due to administrative reasons, so they may report receiving UI if interviewed early in their spell.
} 
a job offer. This job offers effect seems to be very strong in my data. A possible reason why the cited works on Spain may differ on the effect of UI is the treatment given to the unemployment duration variable. ${ }^{35}$

The other new variable included in this second part of the analysis is a dummy that equals 1 if the reason for separation from the previous job was the ending of a TC. As can be seen in table 6 , the estimated coefficient on this variable is positive and significant. This result accords with the idea that TCs have isolated some of the unemployed, making them more employable than the other unemployed. I investigate this issue further by estimating a model in which every variable is interacted with this dummy (see table 7). As can be seen, those jobless workers who are unemployed because their TC came to an end have less duration dependence than the other unemployed (this includes voluntary quits, redundancy, retirement, illness, etc.). Canziani and Petrongolo (2001) estimate a semi-parametric duration model using the panel version of the Spanish Labor Force Survey data for the years 1987-1996 and also find that those jobless workers whose TC ended have higher re-employment probabilities. Jenkins and García-Serrano (2000) using data from the national unemployment benefit administration database find that those who entered UI from a TC have much higher re-employment probabilities than those whose contract was a permanent one.

Table 8, columns 5 and 6, report the duration dependence estimates for those unemployed for whom the reason for separation from their last job was the ending of a TC and for those for whom there was another reason. Figure 7 plots the hazard of leaving unemployment for these two groups of unemployed workers from these regressions. Unemployed workers who came from a TC have greater probability of leaving unemployment at any duration than the others. Secondly, the hazard for those who became jobless because of the ending of a TC is flatter than for the other groups of individuals. That is, although there is negative

\footnotetext{
${ }^{35}$ Alba (1999) excludes from his sample unemployed people of more than 36 months. Bover et al. (2002) treat durations of more than 14 months as censored at 14 months.
} 
duration dependence, it is much smaller than for those individuals that lost their jobs for other reasons. These results also suggest that TCs have increased the employment chances for a group of the unemployed that churns from employment to unemployment frequently. The remaining unemployed have lower probability of re-employment, and this probability is worse at longer durations.

It is interesting to note that education has an insignificant effect those who ended a TC, while it has a positive significant effect for those who became jobless for reasons other than the ending of a TC. One possible explanation is that since people who became unemployed because of the ending of a TC have greater probability of leaving unemployment, they are more attached to the labor market and therefore having a university degree or not does not substantially affect the probability of finding a job. Instead, people that became jobless for other reasons are less attached to the labor market and therefore having a university degree can improve their probability of becoming employed.

Returning to the effects of UI, the coefficients for both groups appear to be positive although larger for those who became unemployed for reasons other than ending a TC. This is consistent with the aforementioned effect of unemployment insurance on the duration of unemployment because the unemployed workers who became unemployed for other reasons experience longer durations of unemployment.

All the results discussed above indicate that the distribution of the duration of unemployment has become more unequal in the early 1990s compared to the mid-1980s. A possible explanation for this fact is the introduction of TCs. As mentioned above, these contracts have generated an increase in the average outflow rate. To the extent that the higher employment chances created by these contracts have not been shared equally among all the unemployed, then the outflow rate from unemployment for those who have not benefited from TCs will not have increased. The above results suggest that the re-employment prob- 
ability of the latter have been reduced. To further investigate this, I re-estimate the above model allowing for a more flexible base-line hazard.

Tables $9 \mathrm{a}$ and $9 \mathrm{~b}$ report the estimates for the whole sample where every variable is interacted with a post-reform dummy (d8594, which takes value 1 for the years 1985-1994). This regression is similar to the one reported in Table 4, except that three different steps of the baseline hazard are allowed. Figure 8 plots the hazard of leaving unemployment for the reference category estimated by this regression for the years before and after the reform. As can be seen, in the years after the reform the last step of the baseline, which corresponds to the LTU, is lower than in the years before the reform. This result is consistent with the results of the previous parametric estimations. That is, conditional on being long-term unemployed, the probability of leaving unemployment after the reform are lower than before.

\section{Conclusion}

In this paper I have analyzed the effects of the introduction of fixed-term contracts on the duration distribution of unemployment in Spain. The motivation was, on the one hand, to study whether this policy impacted different dimensions of the labor market, given the failure to reduce unemployment. On the other hand, since the introduction of temporary contracts has made the labor market more dynamic, an additional motivation was to study the impact of the increase in inflows and outflows from unemployment to employment on the duration distribution of the unemployment.

To answer these questions, I have exploited cross-sectional data available over a very long time period (from 1980 to 1994) that allowed me to analyze the probability of leaving unemployment before and after the introduction of fixed-term contracts in Spain. In particular, I have explored the possibility that fixed-term contracts implied longer duration of unemployment for the long-term unemployed even while it lowered the incidence of LTU due to increased (average) outflow rate. I have found evidence of this effect. In particular, the 
relative probability of leaving unemployment for the short term unemployed versus the long term unemployed increased significantly from the mid 1980s to the early 1990s.

It seems plausible that these changes have been driven by the introduction of TCs, since this was the major institutional change in the time period studied. Clearly, it is possible that during the period of time analyzed there were also some underlying structural changes in the Spanish economy. As discussed, the important fact is that, in the labor market, these other possible changes materialized through temporary contracts.

It is often argued that a high proportion of LTU is a possible cause of high unemployment itself. Although this causality cannot be conclusively inferred (see Machin and Manning, 1999), in the case of Spain it is possible that the limited success of flexibility measures in reducing unemployment could be linked to the fact that TCs have not helped to reduce the duration dependence in unemployment. 
Table 1: Unemployment rate, incidence of LTU and share of TCs for several countries

\begin{tabular}{llrrrrrrrrrrrr}
\hline \hline \multirow{2}{*}{ Denmark } & urate & 1983 & 1984 & 1985 & 1986 & 1987 & 1988 & 1989 & 1990 & 1991 & 1992 & 1993 & 1994 \\
& LTU & 33.0 & - & 7.1 & 5.4 & 5.4 & 6.1 & 7.3 & 7.7 & 8.4 & 9.2 & 10.1 & 8.2 \\
& TCs & - & 12.5 & 12.3 & - & 11.2 & 11.5 & 10.0 & 10.8 & 11.9 & 11.0 & 10.7 & 12.0 \\
\hline \multirow{2}{*}{ France } & urate & 8.1 & 9.7 & 10.1 & 10.2 & 10.4 & 9.8 & 9.3 & 8.9 & 9.5 & 10.4 & 11.7 & 12.3 \\
& LTU & 42.2 & - & 46.8 & 47.8 & 45.5 & 44.8 & 43.9 & 38.3 & 37.3 & 36.1 & 34.2 & 38.3 \\
& TCs & 3.3 & - & 4.7 & - & 7.1 & 7.8 & 8.5 & 10.5 & 10.2 & 10.5 & 10.9 & 11.0 \\
\hline \multirow{2}{*}{ Germany } & urate & 6.9 & 7.1 & 7.2 & 6.5 & 6.3 & 6.2 & 5.6 & 4.8 & 5.6 & 6.6 & 7.9 & 8.4 \\
& LTU & 39.3 & - & 47.9 & 48.9 & 48.2 & 46.7 & 49.0 & 46.3 & 45.5 & 33.5 & - & 44.3 \\
& TCs & 10.0 & - & 10.0 & - & 11.6 & 11.4 & 11.0 & 10.5 & 10.1 & 10.5 & 10.3 & 10.3 \\
\hline \multirow{2}{*}{ Ireland } & urate & 14.0 & 15.5 & 16.8 & 16.8 & 16.6 & 16.1 & 14.7 & 13.4 & 14.8 & 15.4 & 15.6 & 14.3 \\
& LTU & 36.9 & - & 64.7 & 65.2 & 66.4 & 66.0 & 67.3 & 67.2 & 60.3 & - & - & 64.3 \\
& TCs & 6.2 & - & 7.3 & - & 8.6 & 9.1 & 8.6 & 8.5 & 8.3 & 8.7 & 9.4 & 9.5 \\
\hline \multirow{2}{*}{ Italy } & urate & 7.7 & 8.1 & 8.5 & 9.2 & 9.9 & 10.0 & 10.0 & 9.1 & 8.8 & 9.0 & 10.3 & 11.4 \\
& LTU & 57.7 & - & 65.8 & 66.1 & 66.4 & 69.0 & 70.4 & 71.1 & 67.1 & 58.2 & - & 61.5 \\
& TCs & 6.6 & - & 4.8 & - & 5.4 & 5.8 & 6.3 & 5.2 & 5.4 & 7.5 & 6.0 & 7.3 \\
\hline Portugal & urate & 7.8 & 8.5 & 8.7 & 8.4 & 6.9 & 5.5 & 4.9 & 4.6 & 4.0 & 4.2 & 5.7 & 7.0 \\
& LTU & - & - & 56.0 & 56.0 & 56.6 & 51.2 & 48.3 & 48.1 & 38.3 & 30.9 & - & 43.4 \\
& TCs & - & - & - & 14.4 & 16.9 & 18.5 & 18.7 & 18.3 & 16.4 & 11.0 & 9.8 & 9.4 \\
\hline \hline \multirow{2}{*}{ Upain } & urate & 17.5 & 20.3 & 21.7 & 21.0 & 20.1 & 19.1 & 16.9 & 16.2 & 16.4 & 18.5 & 22.8 & 24.1 \\
& LTU & 52.4 & - & 56.7 & 57.6 & 62.0 & 61.5 & 58.5 & 54.0 & 51.1 & 47.4 & 50.1 & 56.1 \\
& TCs & - & - & - & - & 15.6 & 22.4 & 26.6 & 29.8 & 32.2 & 33.5 & 32.2 & 33.7 \\
\hline \hline \multirow{2}{*}{ UK } & urate & 11.1 & 11.1 & 11.5 & 11.5 & 10.6 & 8.7 & 7.3 & 7.1 & 8.8 & 10.1 & 10.5 & 9.6 \\
& LTU & 47.0 & - & 47.0 & 45.9 & 45.9 & 44.7 & 40.8 & 36.0 & 28.1 & 35.4 & - & 45.4 \\
& TCs & 5.5 & - & 7.0 & - & 6.3 & 6.0 & 5.4 & 5.2 & 5.3 & 5.5 & 5.9 & 6.5 \\
\hline & LTU & 13.3 & - & 9.5 & 8.7 & 8.1 & 7.4 & 5.7 & 5.6 & 6.3 & 11.2 & 11.7 & 12.2 \\
\hline
\end{tabular}

Notes: (1) urate is the unemployment rate; $L T U$ is the share of unemployed with spells $\geq 12$ months and TCs is the share of workers under a temporary contract among employed; (2) Since 1991, data on Germany and EU include the new German Länder; (3) Source: OECD (1993, 1996 and 1999). 
Table 2: Sample characteristics

\begin{tabular}{|c|c|c|c|c|c|c|c|}
\hline & $\begin{array}{c}1) \\
1980-94 \\
\end{array}$ & $\begin{array}{c}(2) \\
1980-84 \\
\end{array}$ & $\begin{array}{c}(3) \\
1985-94 \\
\end{array}$ & $\begin{array}{c}(4) \\
1992-94\end{array}$ & $\begin{array}{c}(5) \\
1987-94\end{array}$ & $\begin{array}{c}(6) \\
\text { End TC }\end{array}$ & $\begin{array}{c}(7) \\
\text { Other reasons }\end{array}$ \\
\hline age & $\begin{array}{c}35.738 \\
(13.440)\end{array}$ & $\begin{array}{c}35.010 \\
(13.267)\end{array}$ & $\begin{array}{c}36.041 \\
(13.502)\end{array}$ & $\begin{array}{c}36.667 \\
(14.141)\end{array}$ & $\begin{array}{c}35.926 \\
(13.603)\end{array}$ & $\begin{array}{c}34.632 \\
(13.490)\end{array}$ & $\begin{array}{c}36.317 \\
(13.378)\end{array}$ \\
\hline married & $\begin{array}{c}0.527 \\
(0.499)\end{array}$ & $\begin{array}{c}0.551 \\
(0.497)\end{array}$ & $\begin{array}{c}0.517 \\
(0.499)\end{array}$ & $\begin{array}{c}0.492 \\
(0.499)\end{array}$ & $\begin{array}{c}0.497 \\
(0.500)\end{array}$ & $\begin{array}{c}0.452 \\
(0.498)\end{array}$ & $\begin{array}{c}0.566 \\
(0.495)\end{array}$ \\
\hline $\begin{array}{l}\text { second. or } \\
\text { univ. ed. }\end{array}$ & $\begin{array}{c}0.326 \\
(0.469)\end{array}$ & $\begin{array}{c}0.197 \\
(0.398)\end{array}$ & $\begin{array}{c}0.379 \\
(0.485)\end{array}$ & $\begin{array}{c}0.476 \\
(0.499)\end{array}$ & $\begin{array}{c}0.417 \\
(0.493)\end{array}$ & $\begin{array}{c}0.435 \\
(0.496)\end{array}$ & $\begin{array}{c}0.268 \\
(0.443)\end{array}$ \\
\hline n. of kids & $\begin{array}{c}1.003 \\
(1.253)\end{array}$ & $\begin{array}{c}1.219 \\
(1.416)\end{array}$ & $\begin{array}{c}0.914 \\
(1.168)\end{array}$ & $\begin{array}{c}0.808 \\
(1.047)\end{array}$ & $\begin{array}{c}0.865 \\
(1.124)\end{array}$ & $\begin{array}{c}0.881 \\
(1.133)\end{array}$ & $\begin{array}{l}1.068 \\
(1.307)\end{array}$ \\
\hline $\begin{array}{l}\mathrm{n} \text {. of working } \\
\text { adults }\end{array}$ & $\begin{array}{c}0.718 \\
(0.886)\end{array}$ & $\begin{array}{c}0.699 \\
(0.872)\end{array}$ & $\begin{array}{c}0.728 \\
(0.891)\end{array}$ & $\begin{array}{c}0.751 \\
(0.884)\end{array}$ & $\begin{array}{c}0.762 \\
(0.906)\end{array}$ & $\begin{array}{c}0.766 \\
(0.911)\end{array}$ & $\begin{array}{c}0.694 \\
(0.871)\end{array}$ \\
\hline UI & & & & $\begin{array}{c}0.463 \\
(0.499)\end{array}$ & $\begin{array}{c}0.430 \\
(0.495)\end{array}$ & $\begin{array}{c}0.441 \\
(0.496)\end{array}$ & $\begin{array}{l}0.216 \\
(0.411)\end{array}$ \\
\hline endTC & & & & $\begin{array}{c}0.713 \\
(0.452)\end{array}$ & $\begin{array}{c}0.629 \\
(0.483)\end{array}$ & $\begin{array}{c}1.000 \\
(0.000)\end{array}$ & $\begin{array}{c}0.000 \\
(0.000)\end{array}$ \\
\hline $\begin{array}{l}\text { log local } \\
\text { unemployment }\end{array}$ & $\begin{array}{c}2.692 \\
(0.484)\end{array}$ & $\begin{array}{c}2.423 \\
(0.512)\end{array}$ & $\begin{array}{c}2.803 \\
(0.425)\end{array}$ & $\begin{array}{c}2.691 \\
(0.443)\end{array}$ & $\begin{array}{c}2.781 \\
(0.441)\end{array}$ & $\begin{array}{l}2.800 \\
(0.447)\end{array}$ & $\begin{array}{c}2.747 \\
(0.428)\end{array}$ \\
\hline Total No. of spells & 80,790 & 23,720 & 57,070 & 18,991 & 44,053 & 27,740 & 16,313 \\
\hline
\end{tabular}

Note: (1) Standard deviations in parenthesis; (2) Source: EPA. 
Table 3: Maximum likelihood estimates of the probability of leaving unemployment, Weibull specification: full sample, 1980-1994

\begin{tabular}{lc}
\hline \hline & Coefficient \\
\hline$\alpha$ & 0.841 \\
$\alpha \times d 8594$ & $(0.023)$ \\
& -0.346 \\
constant & $(0.026)$ \\
& -0.865 \\
constant $\times d 8594$ & $0.104)$ \\
age & 0.952 \\
& $(0.124)$ \\
age $\times d 8594$ & -0.011 \\
& $(0.001)$ \\
married & 0.002 \\
& $0.001)$ \\
married $\times d 8594$ & 0.197 \\
second. or univ. ed. & $(0.026)$ \\
second. or univ. ed. $\times d 8594$ & -0.215 \\
n. of kids & $(0.029)$ \\
& -0.094 \\
n. of kids $\times d 8594$ & $0.027)$ \\
& 0.151 \\
n. of working adults & $(0.029)$ \\
n. of working adults $\times d 8594$ & 0.021 \\
& $(0.007)$ \\
log local unemployment & 0.026 \\
log local unemployment $\times d 8594$ & $(0.009)$ \\
& -0.042 \\
mean log-likelihood & $(0.012)$ \\
\hline \hline & 0.018 \\
& $(0.014)$ \\
& -0.304 \\
& $(0.021)$ \\
& 0.081 \\
& $0.025)$ \\
\hline & -2.402 \\
& 80,790 \\
\hline
\end{tabular}

Note: (1) Standard errors in parenthesis; (2) The variable $d 8594$ is equal to 1 for the years 1985 to 1994 and zero otherwise; (3) Source: EPA. 
Table 4: Maximum likelihood estimates of the probability of leaving unemployment, Weibull specification: post reform sample, 1985-1994

\begin{tabular}{lc}
\hline \hline & Coefficient \\
\hline$\alpha$ & 0.402 \\
$\alpha \times d 9294$ & $0.010)$ \\
& 0.257 \\
constant & $0.017)$ \\
& 0.428 \\
constant $\times d 9294$ & $(0.061)$ \\
& -1.128 \\
age & $(0.101)$ \\
& -0.017 \\
age $\times d 9294$ & $(0.001)$ \\
& 0.013 \\
married & $(0.001)$ \\
married $\times d 9294$ & 0.156 \\
second. or univ. ed. & $(0.014)$ \\
second. or univ. ed. $\times d 9294$ & -0.254 \\
& $(0.021)$ \\
n. of kids & -0.070 \\
n. of kids $\times d 9294$ & $(0.012)$ \\
& 0.143 \\
n. of working adults & $(0.019)$ \\
n. of working adults $\times d 9294$ & 0.011 \\
& $(0.005)$ \\
log local unemployment & 0.081 \\
log local unemployment $\times d 9294$ & $(0.008)$ \\
& -0.014 \\
mean log-likelihood & $(0.006)$ \\
\hline \hline & 0.001 \\
& $(0.010)$ \\
& -0.115 \\
& $(0.013)$ \\
& -0.084 \\
& $(0.020)$ \\
\hline & -2.668 \\
& 57,070 \\
\hline
\end{tabular}

Note: (1) Standard errors in parenthesis; (2) The variable $d 9294$ is equal to 1 for the years 1992 to 1994 and zero otherwise; (3) Source: EPA. 
Table 5: Maximum likelihood estimates of the probability of leaving unemployment, Weibull specification: 1983 and 1992

\begin{tabular}{|c|c|}
\hline & Coef. \\
\hline$\alpha$ & $\begin{array}{c}0.738 \\
(0.034)\end{array}$ \\
\hline$\alpha \times d 92$ & $\begin{array}{l}-0.269 \\
(0.039)\end{array}$ \\
\hline constant & $\begin{array}{l}-0.384 \\
(0.168)\end{array}$ \\
\hline constant $\times d 92$ & $\begin{array}{c}0.390 \\
(0.211)\end{array}$ \\
\hline age & $\begin{array}{l}-0.014 \\
(0.001)\end{array}$ \\
\hline age $\times d 92$ & $\begin{array}{c}0.009 \\
(0.002)\end{array}$ \\
\hline married & $\begin{array}{c}0.183 \\
(0.037)\end{array}$ \\
\hline married $\times d 92$ & $\begin{array}{l}-0.344 \\
(0.046)\end{array}$ \\
\hline second. or univ. ed. & $\begin{array}{c}0.023 \\
(0.036)\end{array}$ \\
\hline second. or univ. ed. $\times d 92$ & $\begin{array}{c}0.105 \\
(0.045)\end{array}$ \\
\hline n. of kids & $\begin{array}{c}0.017 \\
(0.011)\end{array}$ \\
\hline n. of kids $\times d 92$ & $\begin{array}{c}0.051 \\
(0.015)\end{array}$ \\
\hline n. of working adults & $\begin{array}{l}-0.047 \\
(0.017)\end{array}$ \\
\hline n. of working adults $\times d 92$ & $\begin{array}{c}0.028 \\
(0.022)\end{array}$ \\
\hline log local unemployment & $\begin{array}{l}-0.282 \\
(0.037)\end{array}$ \\
\hline log local unemployment $\times d 92$ & $\begin{array}{c}0.175 \\
(0.048) \\
\end{array}$ \\
\hline $\begin{array}{l}\text { mean log-likelihood } \\
\text { No. of obs. }\end{array}$ & $\begin{array}{c}-2.353 \\
9,974\end{array}$ \\
\hline
\end{tabular}

Note: (1) Standard errors in parenthesis; (2) The variable $d 92$ is equal to 1 for the year 1992 and zero otherwise; (3) Source: EPA. 
Table 6: Maximum likelihood estimates of the probability of leaving unemployment, Weibull specification: post reform sample, 1987-1994

\begin{tabular}{|c|c|c|c|c|}
\hline & $\begin{array}{l}(1) \\
\text { Coef. }\end{array}$ & $\begin{array}{c}(2) \\
\text { Coef. }\end{array}$ & $\begin{array}{c}(3) \\
\text { Coef. }\end{array}$ & $\begin{array}{l}(4) \\
\text { Coef. }\end{array}$ \\
\hline$\alpha$ & $\begin{array}{c}0.495 \\
(0.009)\end{array}$ & $\begin{array}{c}0.536 \\
(0.009)\end{array}$ & $\begin{array}{c}0.615 \\
(0.009)\end{array}$ & $\begin{array}{c}0.651 \\
(0.010)\end{array}$ \\
\hline constant & $\begin{array}{c}0.133 \\
(0.050)\end{array}$ & $\begin{array}{l}-0.133 \\
(0.051)\end{array}$ & $\begin{array}{l}-0.975 \\
(0.055)\end{array}$ & $\begin{array}{l}-1.181 \\
(0.056)\end{array}$ \\
\hline age & $\begin{array}{l}-0.008 \\
(0.0004)\end{array}$ & $\begin{array}{l}-0.009 \\
(0.0004)\end{array}$ & $\begin{array}{c}-0.005 \\
(0.0004)\end{array}$ & $\begin{array}{l}-0.006 \\
(0.0004)\end{array}$ \\
\hline married & $\begin{array}{l}-0.030 \\
(0.010)\end{array}$ & $\begin{array}{l}-0.124 \\
(0.011)\end{array}$ & $\begin{array}{c}0.050 \\
(0.001)\end{array}$ & $\begin{array}{l}-0.032 \\
(0.011)\end{array}$ \\
\hline second. or univ. ed. & $\begin{array}{c}0.054 \\
(0.010)\end{array}$ & $\begin{array}{c}0.067 \\
(0.010)\end{array}$ & $\begin{array}{c}0.034 \\
(0.010)\end{array}$ & $\begin{array}{c}0.046 \\
(0.011)\end{array}$ \\
\hline n. of kids & $\begin{array}{c}0.057 \\
(0.004)\end{array}$ & $\begin{array}{c}0.064 \\
(0.004)\end{array}$ & $\begin{array}{c}0.048 \\
(0.004)\end{array}$ & $\begin{array}{c}0.053 \\
(0.004)\end{array}$ \\
\hline n. of working adults & $\begin{array}{l}-0.015 \\
(0.005)\end{array}$ & $\begin{array}{l}-0.008 \\
(0.005)\end{array}$ & $\begin{array}{l}-0.008 \\
(0.005)\end{array}$ & $\begin{array}{l}-0.002 \\
(0.006)\end{array}$ \\
\hline log local unemployment & $\begin{array}{l}-0.232 \\
(0.010)\end{array}$ & $\begin{array}{l}-0.234 \\
(0.010)\end{array}$ & $\begin{array}{l}-0.027 \\
(0.011)\end{array}$ & $\begin{array}{l}-0.273 \\
(0.011)\end{array}$ \\
\hline UI & & $\begin{array}{c}0.308 \\
(0.010)\end{array}$ & & $\begin{array}{c}0.271 \\
(0.010)\end{array}$ \\
\hline endTC & & & $\begin{array}{c}0.819 \\
(0.012)\end{array}$ & $\begin{array}{c}0.813 \\
(0.012)\end{array}$ \\
\hline $\begin{array}{l}\text { mean log-likelihood } \\
\text { No. of obs. }\end{array}$ & $\begin{array}{l}-2.973 \\
44,053\end{array}$ & $\begin{array}{l}-2.963 \\
44,053\end{array}$ & $\begin{array}{l}-2.911 \\
44,053\end{array}$ & $\begin{array}{l}-2.904 \\
44,053\end{array}$ \\
\hline
\end{tabular}

Note: (1) Standard errors in parenthesis; (2) Source: EPA. 
Table 7: Maximum likelihood estimates of the probability of leaving unemployment, Weibull specification: reason separation in the last job, 1987-1994

\begin{tabular}{lc}
\hline \hline & Coefficient \\
\hline$\alpha$ & 0.503 \\
$\alpha \times$ endTC & $0.020)$ \\
& 0.180 \\
constant & $(0.023)$ \\
& 0.416 \\
constant $\times$ endTC & $(0.104)$ \\
& -1.281 \\
age & $(0.121)$ \\
age $\times$ endTC & -0.017 \\
& $(0.001)$ \\
married & 0.015 \\
& $(0.001)$ \\
married $\times$ endTC & -0.039 \\
second. or univ. ed. & $(0.021)$ \\
second. or univ. ed. $\times$ endTC & 0.019 \\
& $(0.025)$ \\
n. of kids & 0.219 \\
& $(0.019)$ \\
n. of kids $\times$ endTC & -0.248 \\
n. of working adults & $(0.023)$ \\
n. of working adults $\times$ endTC & 0.062 \\
UI & $(0.008)$ \\
UI $\times$ endTC & -0.017 \\
log local unemployment & $(0.009)$ \\
log local unemployment $\times$ endTC & -0.002 \\
mean log-likelihood & $(0.010)$ \\
\hline \hline & 0.006 \\
& $(0.012)$ \\
& 0.492 \\
& $(0.019)$ \\
& -0.325 \\
& $(0.023)$ \\
& -0.516 \\
& $(0.020)$ \\
& 0.355 \\
& $(0.024)$ \\
& -2.891 \\
& 44,053 \\
\hline
\end{tabular}

Note: (1) Standard errors in parenthesis; (2) The variable endTC is equal to 1

if the reason of last job loss was the ending of a $\mathrm{TC}$ and zero if other reasons;

(3) Source: EPA. 
Table 8: Summary of duration dependence estimates

\begin{tabular}{|c|c|c|c|c|c|}
\hline \multirow{5}{*}{ (I) } & & $\overline{(1)}$ & 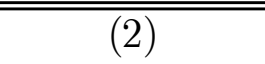 & $\overline{(3)}$ & $\overline{(4)}$ \\
\hline & & 1980-1984 & 1985-1994 & 1985-1991 & 1992-1994 \\
\hline & $\alpha$ & 0.841 & 0.495 & 0.402 & 0.659 \\
\hline & & $(0.023)$ & $(0.008)$ & $(0.010)$ & $(0.014)$ \\
\hline & Source & Table 3 & Table 3 & Table 4 & Table 4 \\
\hline \multirow{5}{*}{$(\mathrm{II})^{(*)}$} & & $(5)$ & (6) & & \\
\hline & & End TC & Other reasons & & \\
\hline & $\alpha$ & 0.683 & 0.503 & & \\
\hline & & $(0.011)$ & $(0.020)$ & & \\
\hline & Source & Table 7 & Table 7 & & \\
\hline
\end{tabular}

${ }^{(*)}$ Includes same regressors as in (I) as well as UI dummy.

Note: (1) Standard errors in parenthesis; (2) Source: EPA.

Table 9a: Baseline hazard estimates

\begin{tabular}{lcc}
\hline \hline & spell months & Coefficient \\
\hline step1 & 1 to 5 & -0.548 \\
& & $(0.048)$ \\
step1 $\times d 8594$ & & -0.355 \\
& & $(0.056)$ \\
step2 & 6 to 11 & -1.218 \\
& & $(0.025)$ \\
step2 $\times$ d8594 & & -0.328 \\
& & $(0.026)$ \\
step 3 & 12 to 36 & -1.733 \\
& & $(0.044)$ \\
step3 $\times d 8594$ & & -1.157 \\
& & $(0.051)$ \\
\hline \hline
\end{tabular}

Note: (1) Standard errors in parenthesis; (2) Source: EPA. 
Table 9b: Maximum likelihood semi-parametric estimates of the probability of leaving unemployment: full sample, 1980-1994

\begin{tabular}{lc}
\hline \hline & Coefficient \\
age & -0.101 \\
age $\times d 8594$ & $0.005)$ \\
& 0.031 \\
married & $(0.006)$ \\
married $\times d 8594$ & 0.177 \\
& $(0.009)$ \\
second. or univ. ed. & -0.187 \\
& $0.009)$ \\
second. or univ. ed. $\times d 8594$ & -0.073 \\
& $(0.015)$ \\
n. of kids & 0.111 \\
& $(0.016)$ \\
n. of kids $\times d 8594$ & 0.013 \\
& $(0.004)$ \\
n. of working adults & 0.023 \\
n. of working adults $\times d 8594$ & $(0.005)$ \\
log local unemployment & -0.038 \\
& $(0.007)$ \\
log local unemployment $\times d 8594$ & 0.025 \\
& $(0.008)$ \\
\hline mean log-likelihood & 0.171 \\
No. of obs. & $(0.014)$ \\
\hline \hline
\end{tabular}

Note: (1) Standard errors in parenthesis; (2)The variable $d 8594$ is equal to 1 for the years 1985 to 1994 and zero otherwise; (3) Source: EPA. 


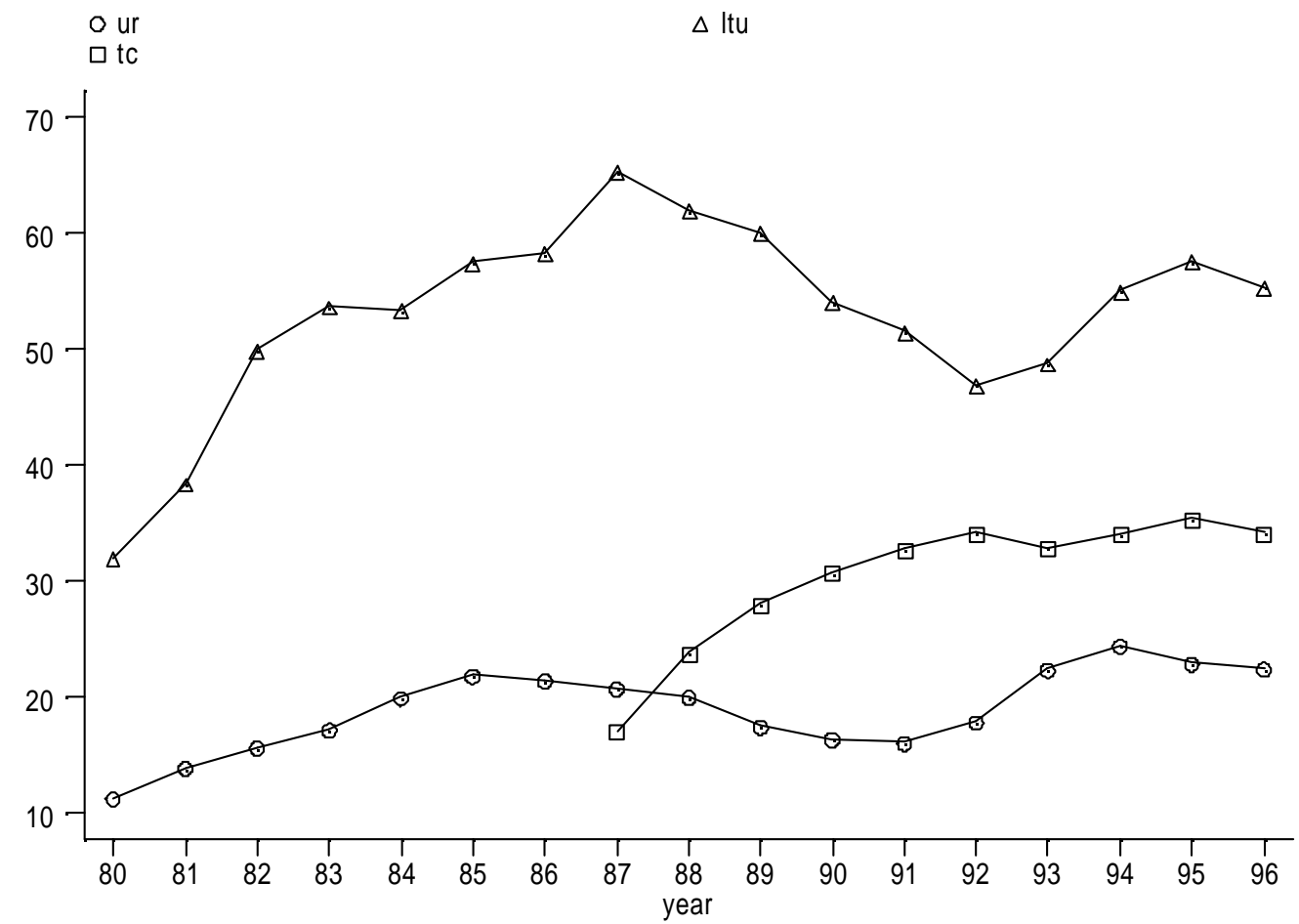

Figure 1: Unemployment rate, proportion of LTU and share of temporary contracts, 1980-1996. Source: EPA.

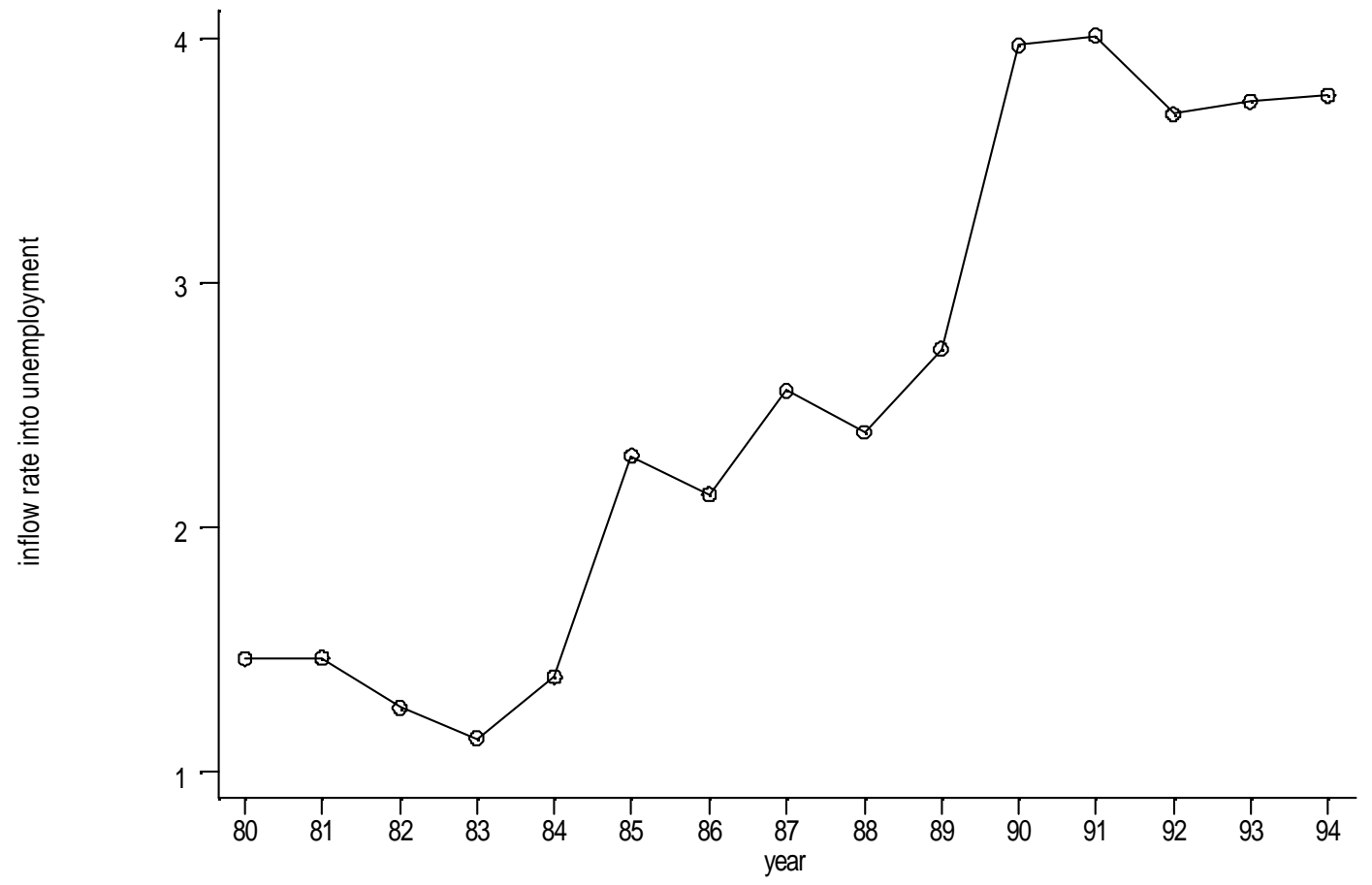

Figure 2: Evolution of inflow rates from employment into unemployment, 1980-1994. Source: MLR. 


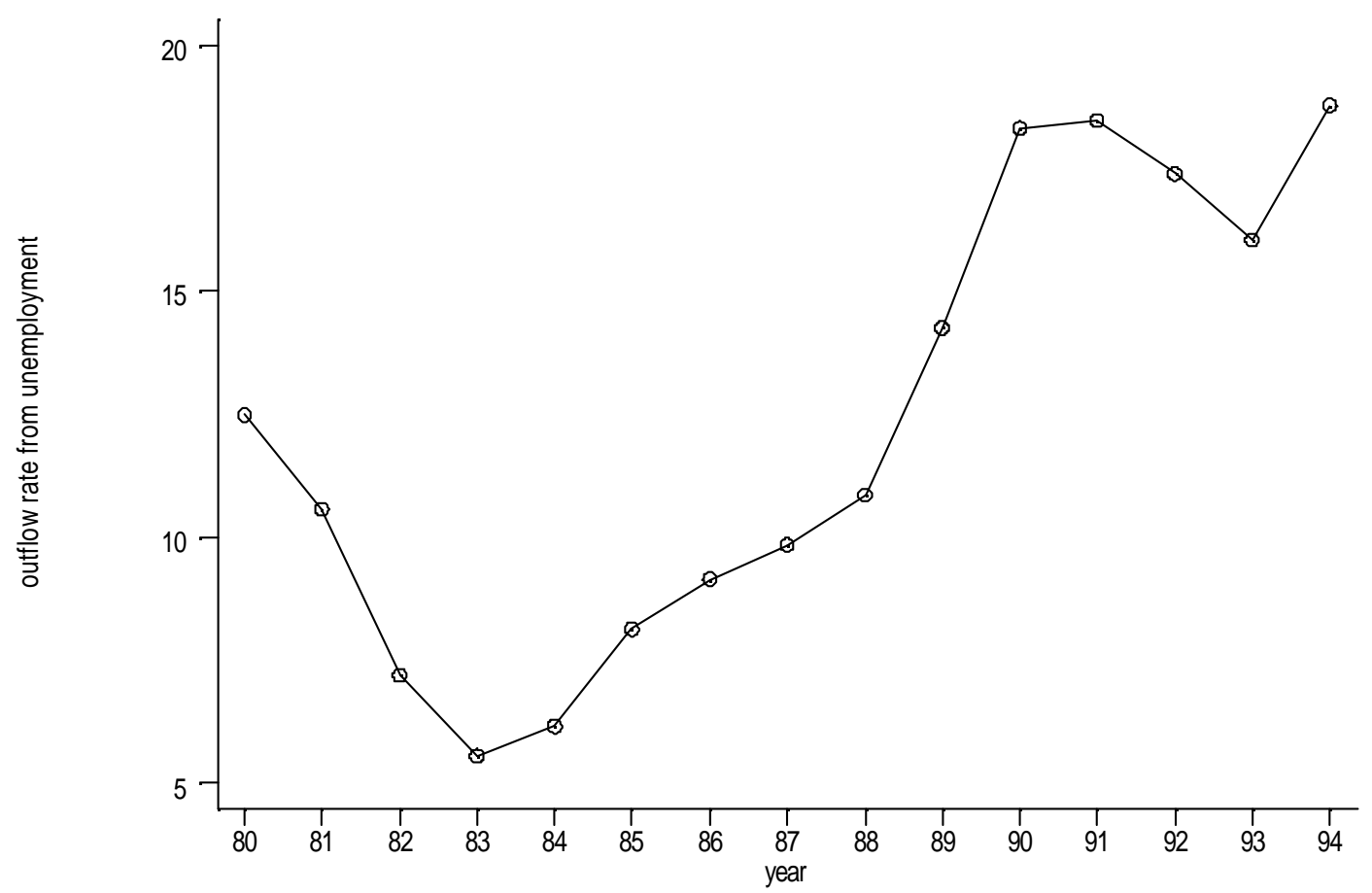

Figure 3: Evolution of outflow rates from unemployment into employment, 1980-1994. Source: MLR.

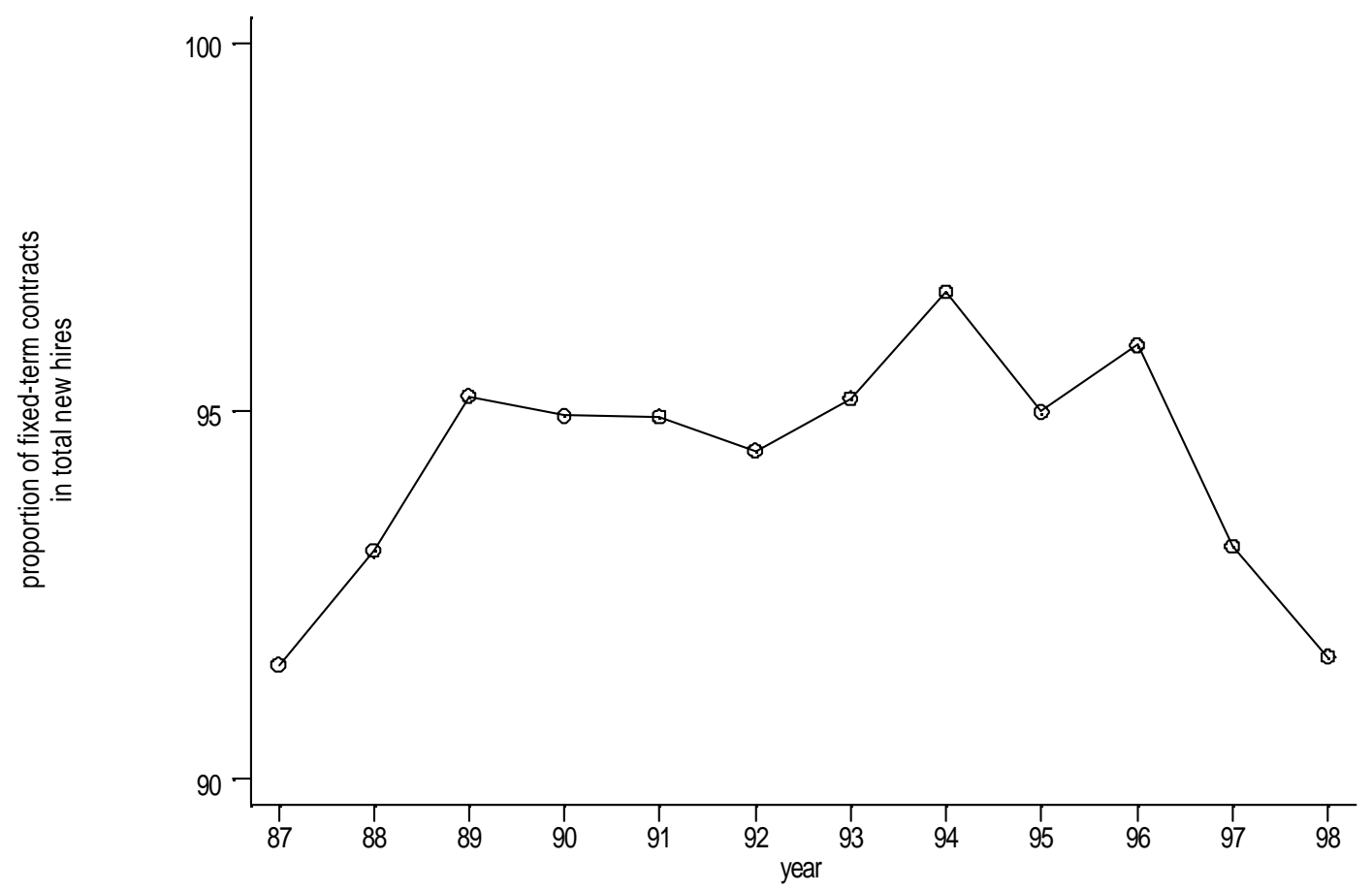

Figure 4: Evolution of the share of fixed-term contracts in new hires, 1987-1998. Source: MLR. 


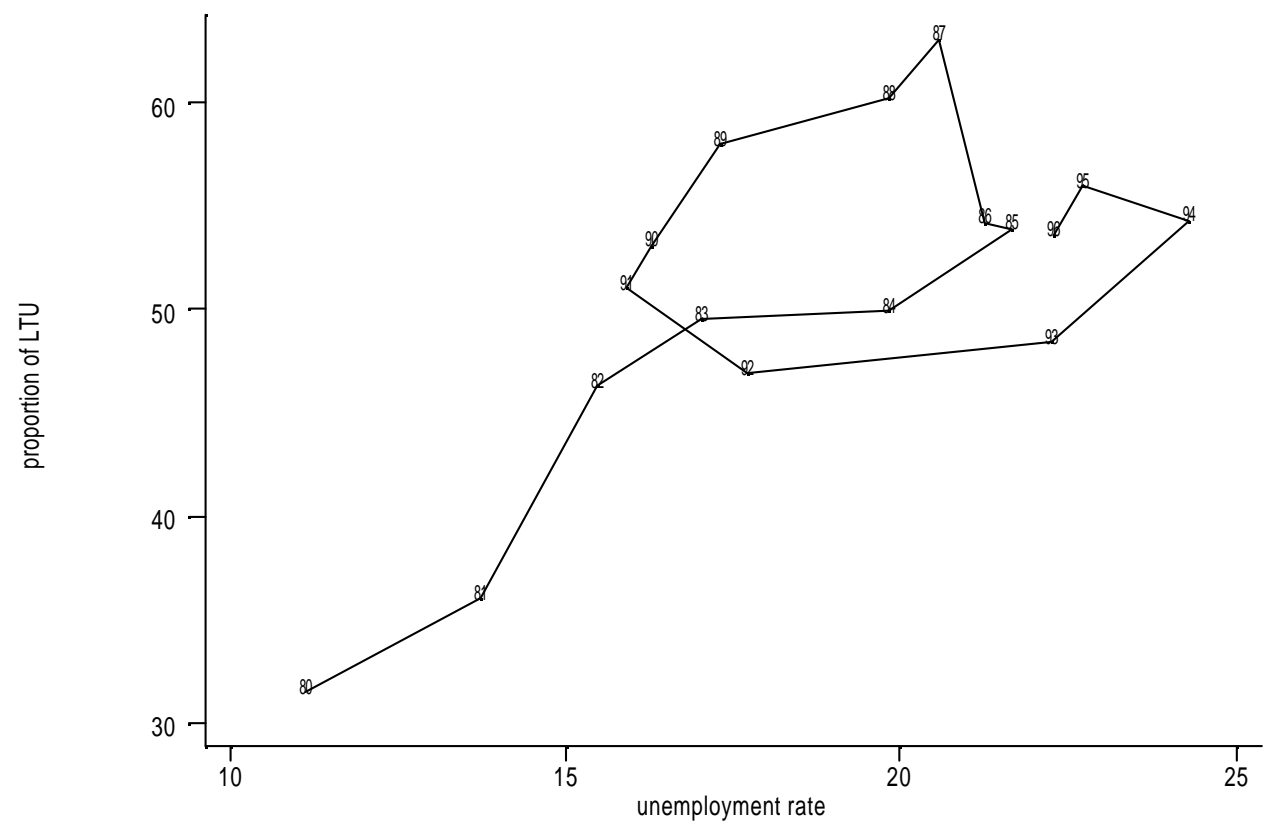

Figure 5: The incidence of LTU and the unemployment rate, 1980-1996. Source: EPA.

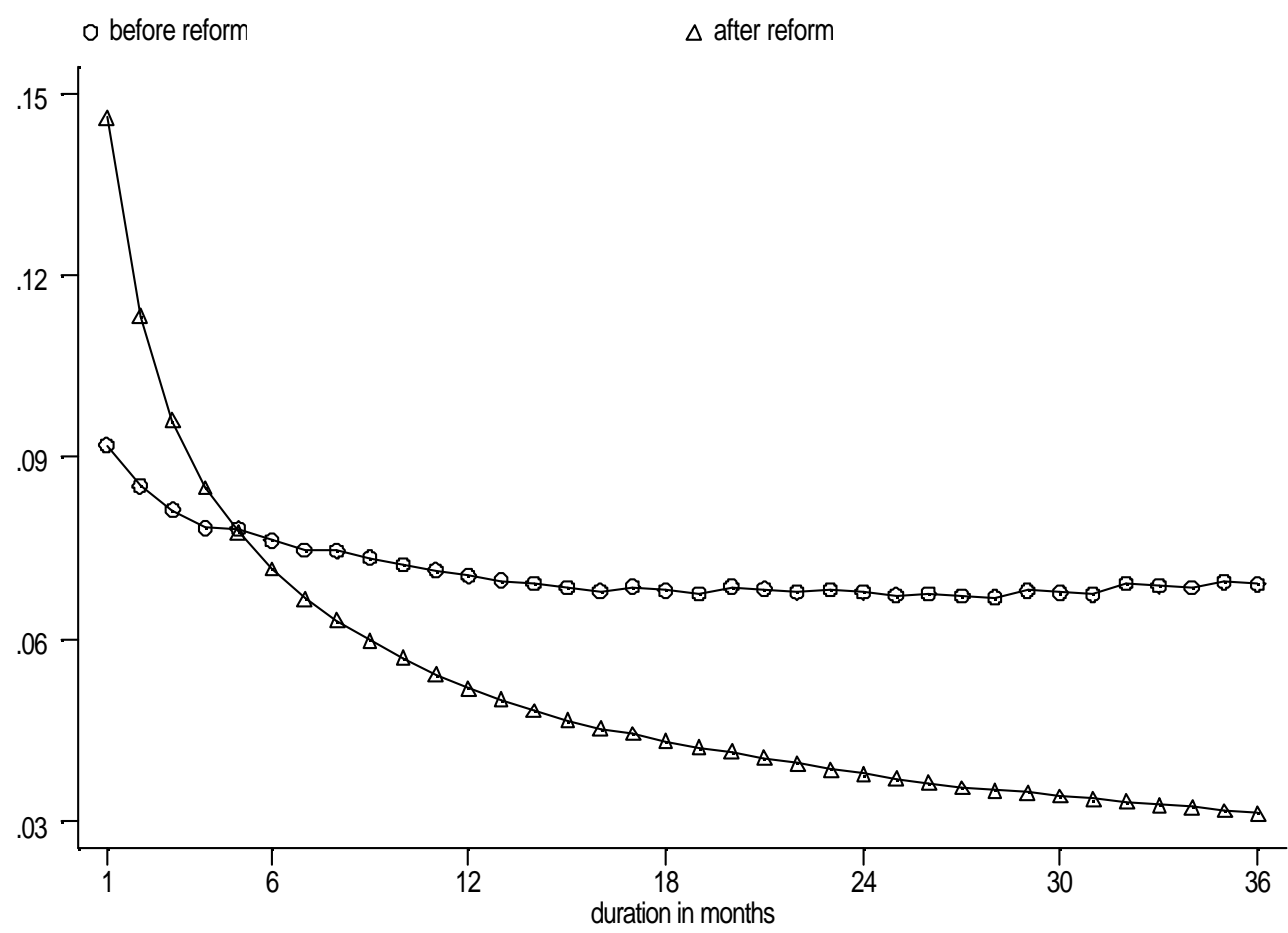

Figure 6: Hazard of leaving unemployment for the reference worker before and after the introduction of TC. Ref. category: age 35, not married, primary ed. or below, no kids, no working adults in household (see Table 3). 


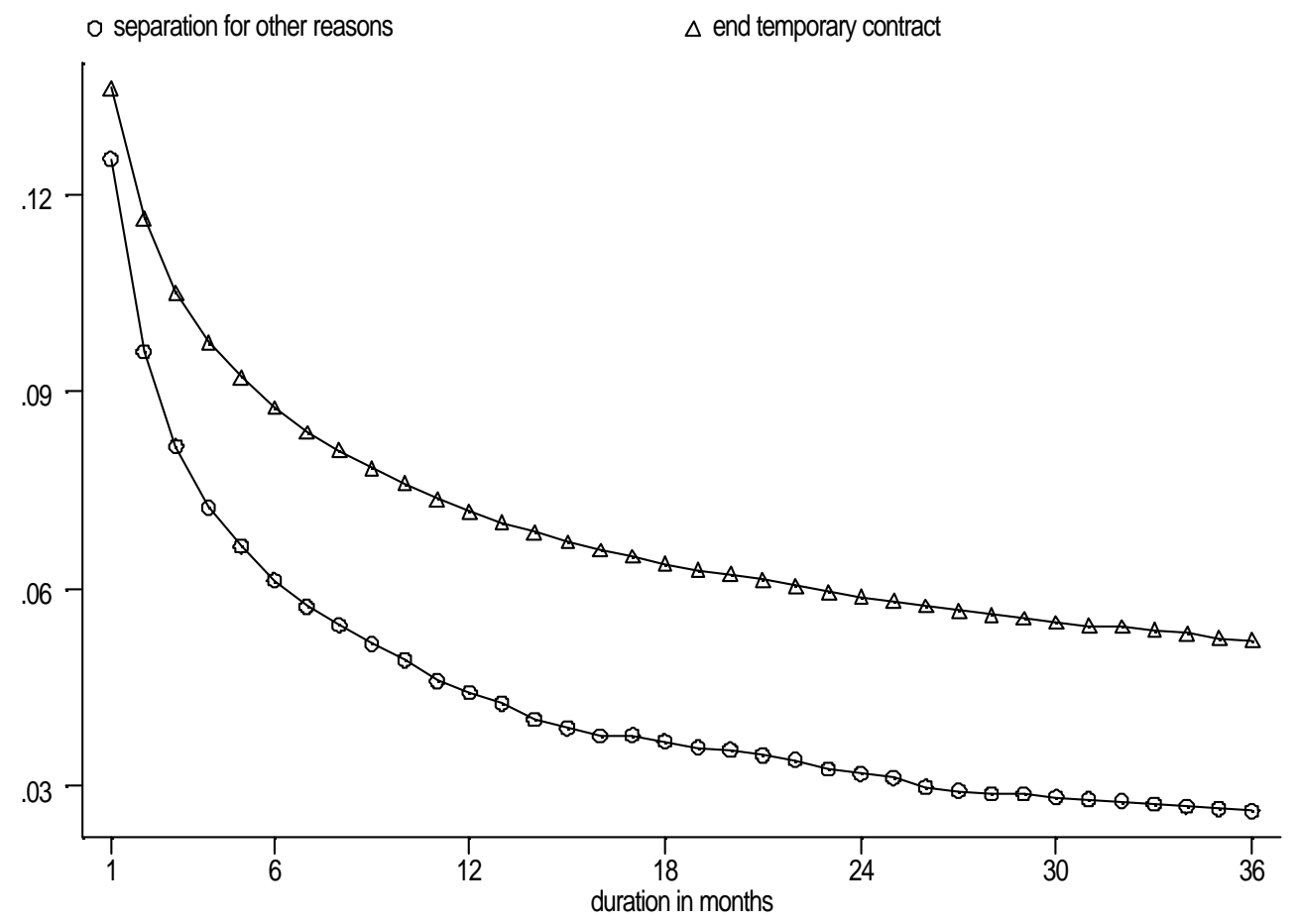

Figure 7: Hazard of leaving unemployment for workers who became jobless because ending of TC and for other reasons. Ref. category: age 35, not married, primary ed. or below, no kids, no working adults in household, no UI (see Table 7).

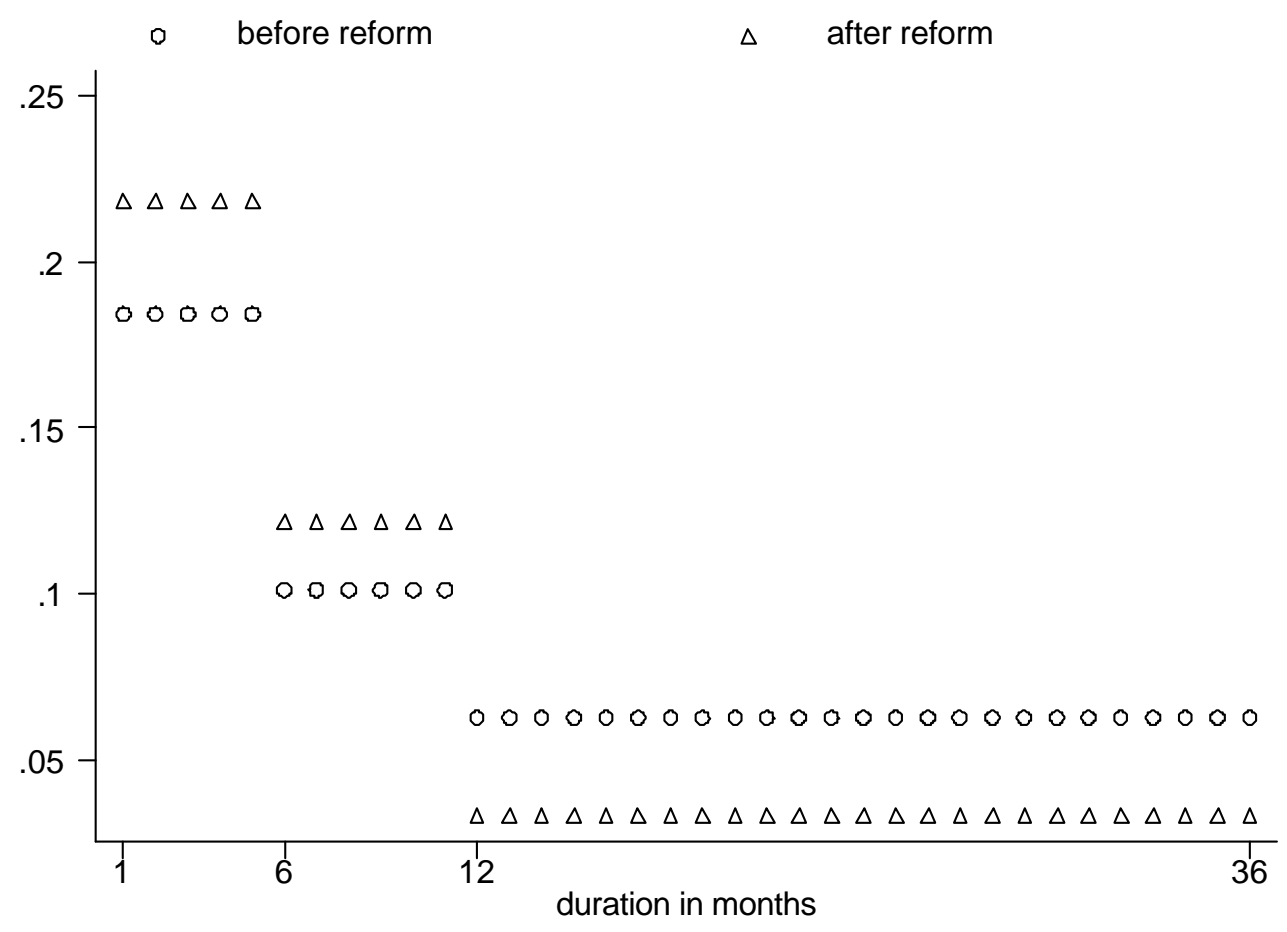

Figure 8: Hazard of leaving unemployment for the reference worker before and after the introduction of TC. Ref. category: age 35, not married, primary ed. or below, no kids, no working adults in household (see Table 9a, 9b). 


\section{References}

[1] Aguirregabiria, V. and C. Alonso-Borrego (1999), "Labor contracts and flexibility: evidence from a labor market reform in Spain", Universidad Carlos III Working Paper No 99-27.

[2] Alba, A. (1999): "Explaining the transitions out of unemployment in Spain: the effect of unemployment insurance", Applied Economics, 31, 183-193.

[3] Alonso-Borrego, C., J. Fernandez-Villaverde and J. E. Galdón-Sánchez (1999), "A general dynamic equilibrium model of temporary contracts", Federal Reserve Bank of Minneapolis mimeo.

[4] Andrés, J., J. García and S. Jiménez (1989): "La incidencia y la duración del desempleo masculino en España", Moneda y Crédito, 189, 75-124.

[5] Atkinson, A. B. and J. Micklewright (1991): "Unemployment compensation and labour market transitions: a critical review", Journal of Economic Literature, 29, 1679-1727.

[6] Bentolila, S. and J. J. Dolado (1994), "Labour flexibility and wages: lessons from Spain", Economic Policy, 18, 53-99.

[7] Blanchard, O. J. and P. Diamond (1994), " Ranking, Unemployment Duration, and Wages", Review of Economic Studies, 61, 417-434.

[8] Booth, A., J.J. Dolado and J. Frank (2002), "Symposium on temporary work. Introduction", Economic Journal, Features: Symposium on Temporary Work, F181-F188.

[9] Bover, O., M. Arellano and S. Bentolila (2002), "Unemployment duration, benefit duration, and the business cycle", The Economic Journal, 112 (479), 223-265.

[10] Canziani, P. and B. Petrongolo (2001): "Firing costs and Stigma: A theoretical analysis and evidence from micro data", European Economic Review (45)10, 1877-1906.

[11] García-Pérez, J. I (1997): "Las tasas de salida del empleo y el desempleo en España (1978-1993)", Investigaciones Económicas, vol XXI (1), 29-53.

[12] García-Serrano, C. (1998): "Worker turnover and job reallocation:the role of fixed-term contracts", Oxford Economic Papers 50, 709-725.

[13] Grubb, D. and W. Wells (1993), "Employment Regulation and patterns of work in EC countries", OECD Economic Studies, 21, 7-58.

[14] Güell, M. (1999): "The effects of fixed-term contracts on the duration distribution of unemployment: the Spanish case", mimeo London School of Economics.

[15] Güell, M. (2000): "Fixed-term Contracts and Unemployment: an Efficiency Wage Analysis", Industrial Relations Section, Princeton University, Working Paper No. 433. 
[16] Güell, M. and B. Petrongolo (2000): "Workers' transitions from temporary to permanent employment: the Spanish case", Centre for Economic Performance, London School of Economics, Discussion Paper 438.

[17] Jenkins, S. P. and C. García-Serrano (2000): "Re-employment probabilities for Spanish men: what role does the unemployment benefit system play?" Institute for Labour Research Discussion Paper 00/55, University of Essex.

[18] Layard, R., S. J. Nickell and R. Jackman (1991), Unemployment: Macroeconomic Performance and the Labour Market, Oxford University Press.

[19] Machin, S. and A. Manning (1999): "The causes and consequences of long-term unemployment in Europe" in Orley Ashenfelter and David Card (eds.), Handbook of Labor Economics, Volume 3. Amsterdam: North-Holland.

[20] Mortensen, D. T. (1970): "Job search, the duration of unemployment and the Phillips curve", The American Economic Review, 60, 847-862.

[21] Mortensen, D. T. (1977): "Unemployment insurance and job search decisions", Industrial and Labor Relations Review, 30 (4), 505-517.

[22] Nickell, S. J. (1979a): "Estimating the probability of leaving unemployment", Econometrica, 47 (5), 1249-1266.

[23] Nickell, S. J. (1979b): "The effect of unemployment and related benefits on the duration of unemployment", The Economic Journal, 89, 34-49.

[24] OECD (1993), Employment Outlook, Paris.

[25] OECD (1994), The OECD Jobs Study, Paris.

[26] OECD (1996), Employment Outlook, Paris.

[27] OECD (1999), Employment Outlook, Paris.

[28] OECD (2002), Employment Outlook, Paris.

[29] Saint-Paul, G. (1996), "Dual labor markets, a macroeconomic perspective", Cambridge, MA: MIT Press.

[30] Schmitt, J. and J. Wadsworth (1993): "Unemployment benefit levels and search activity", Oxford Bulletin of Economics and Statistics, 55 (1), 1-24.

[31] Toharia, L. (1997), Spain, Labour Market Studies series No. 1, Employment and Social Affairs, European Commission, Brussels.

[32] van den Berg, G. J. and B. van der Klaauw (2001): "Combining micro and macro unemployment data", Journal of Econometrics 102, 271-309.

[33] Wadsworth, J. (1990): "Unemployment benefits and search effort in the UK labour market", Economica, 58, 17-34. 


\section{Appendix}

\section{A. The duration of unemployment in the EPA}

Table 10: The duration of the unemployment in the EPA

\begin{tabular}{ccc}
\hline \hline until $1987(\mathrm{I})$ & $1987(\mathrm{II})-1991(\mathrm{VI})$ & from 1992 (I) \\
\hline How long have you & How long have you & Which day did you \\
been looking for a job? & been looking for a job? & start looking for a job? \\
Less than 1 month & If less than 2 years, & Month \\
1 to 3 months & number of months & \\
3 to 6 months & & Year \\
6 months to 1 year & If 2 years or more, & \\
1 to 2 years & number of years & \\
2 years or more & & \\
\hline \hline
\end{tabular}

B. Unemployment benefits and duration

Table 11: Correlation of UI receipt and duration of unemployment

\begin{tabular}{lc}
\hline \hline & $1987-1994$ \\
\hline all durations & -0.109 \\
less than 3 months & 0.093 \\
less than 6 months & 0.152 \\
more than 6 months & -0.184 \\
more than 12 months & -0.214 \\
\hline \hline
\end{tabular}

\section{Composition of unemployment inflows}

Table 12. Testing for the constancy of inflow composition

\begin{tabular}{lccccccc}
\hline \hline \multirow{4}{*}{ age } & $(1)$ & $(2)$ & $(3)$ & $(4)$ & $(5)$ & $(6)$ & $(7)$ \\
& $1987-89$ & $1988-90$ & $1989-91$ & $1990-92$ & $1991-93$ & $1992-94$ & $1987-94$ \\
\cline { 2 - 7 } married & 2.27 & 6.79 & 2.12 & 4.94 & 1.05 & 6.29 & 13.11 \\
& $(0.32)$ & $(0.03)$ & $(0.35)$ & $(0.08)$ & $(0.59)$ & $(0.04)$ & $(0.07)$ \\
second. or univ. ed. & 0.44 & 1.11 & 2.09 & 0.62 & 0.65 & 2.16 & 6.16 \\
& 1.87 & 1.26 & 4.69 & 6.09 & 4.84 & 2.44 & 9.29 \\
n. of kids & $(0.39)$ & $(0.53)$ & $(0.10)$ & $(0.05)$ & $(0.09)$ & $(0.29)$ & $(0.24)$ \\
& $0.40)$ & $(0.57)$ & $(0.35)$ & $(0.73)$ & $(0.72)$ & $(0.34)$ & $(0.52)$ \\
n. of working adults & 0.00 & 3.21 & 2.40 & 0.40 & 0.99 & 5.17 \\
& $(0.79)$ & $(1.00)$ & $(0.20)$ & $(0.30)$ & $(0.81)$ & $(0.61)$ & $(0.63)$ \\
& 2.19 & 2.14 & 4.02 & 2.21 & 1.76 & 0.33 & 4.84 \\
No. of obs. & $(0.33)$ & $(0.34)$ & $(0.13)$ & $(0.33)$ & $(0.41)$ & $(0.84)$ & $(0.67)$ \\
\hline \hline
\end{tabular}

Note: (1) Reported $\chi^{2}(2)$ in columns (1) to (6) and $\chi^{2}(7)$ in column (7);

(2) p-value in parenthesis; (3) all regressions include year dummies; (4) Source: EPA. 